\title{
In-situ TEM investigation of nano-scale helium bubble evolution in tantalum-doped tungsten at $800{ }^{\circ} \mathrm{C}$
}

DOI:

10.1016/j.jnucmat.2021.152910

\section{Document Version}

Accepted author manuscript

Link to publication record in Manchester Research Explorer

\section{Citation for published version (APA):}

Ipatova, I., Greaves, G., Pacheco Gutierrez, S., Middleburgh, S., Rushton, M., \& Jimenez-Melero, E. (2021). In-situ TEM investigation of nano-scale helium bubble evolution in tantalum-doped tungsten at $800^{\circ} \mathrm{C}$. Journal of Nuclear Materials, 550, [152910]. https://doi.org/10.1016/j.jnucmat.2021.152910

\section{Published in:}

Journal of Nuclear Materials

\section{Citing this paper}

Please note that where the full-text provided on Manchester Research Explorer is the Author Accepted Manuscript or Proof version this may differ from the final Published version. If citing, it is advised that you check and use the publisher's definitive version.

\section{General rights}

Copyright and moral rights for the publications made accessible in the Research Explorer are retained by the authors and/or other copyright owners and it is a condition of accessing publications that users recognise and abide by the legal requirements associated with these rights.

\section{Takedown policy}

If you believe that this document breaches copyright please refer to the University of Manchester's Takedown Procedures [http://man.ac.uk/04Y6Bo] or contact uml.scholarlycommunications@manchester.ac.uk providing relevant details, so we can investigate your claim.

\section{OPEN ACCESS}




\title{
In-situ TEM investigation of nano-scale helium bubble
}

\section{evolution in tantalum-doped tungsten at $800{ }^{\circ} \mathrm{C}$}

\author{
I. Ipatova $^{\mathrm{a}^{*}}$, G. Greaves ${ }^{\mathrm{b}}$, S. Pacheco-Gutiérrez ${ }^{\mathrm{c}}$, S.C. Middleburgh ${ }^{\mathrm{a}}$, M.J.D. Rushton ${ }^{\mathrm{a}}$, \\ E. Jimenez-Melero ${ }^{\mathrm{d}}$ \\ ${ }^{a}$ Nuclear Fututres institute, Bangor University, Dean Street, \\ Bangor Gwynedd, LL57 1 UT, UK \\ ${ }^{b}$ School of Computing and Engineering, University of Huddersfield, \\ Huddersfield, HD1 3DH, UK \\ ${ }^{c} U K A E A$ - RACE, Culham Science Centre, Abingdon, OX14 3DB, UK \\ ${ }^{d}$ Materials Performance Centre, Department of Materials, The University of Manchester, \\ Manchester M13 9PL, UK
}

\author{
Corresponding author (*): \\ Nuclear Futures Institute \\ Bangor University \\ Dean Street \\ Bangor Gwynedd \\ LL57 1UT \\ United Kingdom \\ Tel.: +447849290480 \\ Email: i.ipatova@bangor.ac.uk
}




\begin{abstract}
The aim of this work is to probe the helium induced defect production and accumulation in $40 \mathrm{keV} \mathrm{He}{ }^{+}$irradiated polycrystalline $\mathrm{W}$ and its alternative alloy $\mathrm{W}-5 \mathrm{wt} . \% \mathrm{Ta}$ using transmission electron microscopy (TEM) combined with in-situ helium irradiation at $800^{\circ} \mathrm{C}$. A maximum damage level of $1 \mathrm{dpa}$ with a maximum He-to-dpa ratio of 5.5 at $\% /$ dpa has been reached in this work for both materials, which corresponds to an ion fluence of $7.33 \times 10^{16}$ $\mathrm{He}^{+} / \mathrm{cm}^{2}$. The presence of radiation-induced dislocation loops was not observed at this temperature. The low density of the incipient bubbles in $\mathrm{W}$ has been already detected at $0.004 \mathrm{dpa}$, which corresponds to a fluence of $3.3 \times 10^{14} \mathrm{He}^{+} / \mathrm{cm}^{2}$. The experiments conducted at $800{ }^{\circ} \mathrm{C}$ have shown that the addition of $5 \mathrm{wt} . \%$ of tantalum into tungsten may diminish the binding of He ions with vacancies into complexes, which serve as the core of the bubble, thus hindering helium bubble formation below $0.02 \mathrm{dpa}$ and their further growth and population at higher damage levels. By exceeding the damage dose $\geq 0.3 \mathrm{dpa}$, a progressive transition from a spherical to a faceted shape of the bubbles has been observed in W but not in the W-5Ta alloy. At $1 \mathrm{dpa},>80 \%$ of the bubbles in $\mathrm{W}$ were of the faceted type with the facet planes of $\{110\}$.
\end{abstract}

Keywords: W/W-5Ta; fusion materials; in-situ helium exposure; faceted helium defects; transmission electron microscopy; bubble detection. 


\section{Introduction}

Tungsten and its engineered alloys are the preferred choice as armour material for plasma-facing components (PFCs) by the nuclear fusion community, and therefore lie at the heart of the international roadmap for the realisation and deployment of fusion reactor technology $[1,2]$. In ITER, the divertor design includes $\mathrm{W}$ monoblocks in the inner and outer vertical targets in each water-cooled cassette assembly [3]. The divertor itself is intended to serve as the plasma power exhaust, particle control (deuterium/tritium (DT) and $\mathrm{He}$ repumping), also functioning as a screen for impurities, reducing contamination [4]. The peak power flux density values for the ITER design range from $8 \mathrm{MW} \mathrm{m}^{-2}$ at most in the nonnuclear phases $\left(\mathrm{H} / \mathrm{He}\right.$ discharges) to $10 \mathrm{MWm}^{-2}$ in the nuclear phases (DT burning discharges), corresponding to $\mathrm{W}$ surface temperatures of $\sim 800{ }^{\circ} \mathrm{C}$ and $\sim 1100{ }^{\circ} \mathrm{C}$ respectively [5]. This may increase to as much as $20 \mathrm{MWm}^{-2}$ during transient events at the monoblock surface [6]. Radiation-induced damage levels in ITER divertor monoblocks are predicted to be $\sim 0.1$ dpa after a four-year ITER nuclear operation phase, prior to cassette replacement of the first divertor, and $\sim 0.5 \mathrm{dpa}$ for permanent divertor components during ITER's end-of-life operation [6].

An ITER-like divertor design for the future fusion demonstration power plant (DEMO) is being considered [7], alongside alternative configurations able to handle the more demanding radiation environment in the inner target of the divertor [8]. Besides this, DEMO is envisaged to comprise a first wall with a $\mathrm{W}$ armour joint to a reduced-activation ferritic/martensitic (RAFM) steel $[9,10]$, with predicted surface heat fluxes of $0.5-1.2 \mathrm{MWm}^{-2}[10,11]$. The expected lowest shield temperatures for $\mathrm{W}$ armour materials range from $\sim 500{ }^{\circ} \mathrm{C}$ in the first wall up to $>800-900{ }^{\circ} \mathrm{C}$ in proposed He-cooled divertor designs and $>1700{ }^{\circ} \mathrm{C}$ in the divertor armour surface [12], whereas neutron bombardment is 
estimated to cause $\sim 4 \mathrm{dpa}$ in the $\mathrm{W}$ armour at the end-of-life of $\mathrm{W}-\mathrm{Cu}$ plasma-facing components in DEMO [13].

Tungsten is characterised by a relatively low ductile-to-brittle-temperature (DBTT), namely $\sim 200-400{ }^{\circ} \mathrm{C}$ [14-17], which can increase progressively with damage level due to the radiation fields inside the fusion reactor core up to $\sim 800-1000{ }^{\circ} \mathrm{C}[18,19]$. Thermal cycling across the DBTT from temperatures between $70-120{ }^{\circ} \mathrm{C}$ up to the maximum surface temperature in $\mathrm{W}$ mock-ups during High-Heat-Flux (HHF) tests does not induce the formation of macro-cracks. However, macro-cracks are observed at a heat load of $20 \mathrm{MWm}^{-2}$ with the surface temperature approaching $2000{ }^{\circ} \mathrm{C}$ [3]. The highest temperature for safe operation of $\mathrm{W}$ components is limited by the resistance to creep, low-cycle fatigue, helium embrittlement and recrystallization [20, 21]. Mechanical test data at $800{ }^{\circ} \mathrm{C}$ constitute a representative property database for $\mathrm{W}$ monoblocks that is compared to their performance under HHF tests and is also used as key input for the universal slope method aimed at correlating tensile properties and fatigue performance of W monoblocks [3]. Plasma exposure of W-based PFCs causes radiation-induced lattice damage, surface sputtering, hydrogen isotope retention and He accumulation and diffusion into the bulk structure [22]. The latter effect can lead to bubble formation and potential blistering and, as a consequence, embrittlement at low temperatures and ductility loss at high temperatures [22]. Additionally, $\mathrm{W}$ exposure to $\mathrm{He}$ ions in the $\mathrm{eV}$ energy regime $(>20-30 \mathrm{eV})$, where physical sputtering does not play a significant role in changes to surface morphology, at temperatures $>700{ }^{\circ} \mathrm{C}$ and a minimal He fluence of $\sim 10^{25} \mathrm{~m}^{-2}$ induces the formation of 'nanostructured or fuzzy W' on the material surface $[5,23,24]$.

In this work we have applied extensive in-situ damage and microstructural analysis techniques to observe $\mathrm{W}$ and $\mathrm{W}-5 \mathrm{wt} . \% \mathrm{Ta}(\mathrm{W}-5 \mathrm{Ta})$ materials at $800{ }^{\circ} \mathrm{C}$ and exposed to 40 $\mathrm{keV} \mathrm{He}^{+}$irradiations at incremental damage levels from only 0.004 dpa up to $1 \mathrm{dpa}$ with a 
maximum He-to-dpa ratio of 5.5 at $\% /$ dpa. Tantalum alloying is one of the proposed engineering solutions to overcome the inherent drawbacks of $\mathrm{W}$ as a structural material, since Ta is reported to shift the onset of $\mathrm{W}$ recrystallization [25-28]. It has also been shown to reduce the vacancy mobility and to consequently delay void formation at $800{ }^{\circ} \mathrm{C}$ under proton irradiation [29]. In W-5Ta, voids were not found up to a damage level of $0.3 \mathrm{dpa}$, however, the excess of free vacancies present in the $\mathrm{W}-5 \mathrm{Ta}$ irradiated at $800^{\circ} \mathrm{C}$ led to the formation of visible voids in TEM study after post-irradiation annealing of the sample at $1000{ }^{\circ} \mathrm{C}$. At lower temperatures the presence of Ta also retards the mobility of self-interstitial atoms (SIAs) and interstitial $\mathrm{a} / 2<111>$ dislocation loops under irradiation at lower temperatures, and consequently the loop growth and coalescence, attaining saturation in loop dimensions at relatively low damage levels $[30,31]$. Ta is also observed to hinder the surface blistering in $\mathrm{W}$ under high-fluence deuterium plasma irradiation [32]. In addition, dual beam and sequential irradiation experiments have shown to shift the fluence threshold for fuzz formation higher in $\mathrm{W}-\mathrm{Ta}$ alloys at $950^{\circ} \mathrm{C}$ as the ratio of $\mathrm{D}^{+} / \mathrm{He}^{+}$ions increases due to a significant D de-trapping at that temperature which led to the fast diffusion and escape of the implanted species [33]. The main research objective is to demonstrate the effect of the presence of $\mathrm{Ta}$ solute atoms in $\mathrm{W}$-Ta binary system on response to radiation under cumulative helium beam exposure at an elevated temperature of $800{ }^{\circ} \mathrm{C}$ which remains largely unexplored. The results obtained in this work are important to the fusion community helping to expand the pallet of candidate structural materials for future fusion devices that are more resistant to $\mathrm{He}+$ induced surface damage. This data will also help to validate predictive models of the expected in-service degradation of fusion construction materials, so that more advanced alloy compositions with optimised properties can be designed and developed for the fusion reactors. 


\section{Materials}

The initial $1 \mathrm{~mm}$-thick W sheet (99.95\%) was provided by Goodfellow Cambridge Ltd. The as-received $\mathrm{W}$ material was annealed in vacuum at $1400{ }^{\circ} \mathrm{C}$ for $2 \mathrm{~h}$ for recrystallization. The W-5Ta alloy was instead produced by Plansee AG via powder metallurgy. W-5Ta was double forged and then annealed at $1600{ }^{\circ} \mathrm{C}$ for $1 \mathrm{~h} \mathrm{[34].} \mathrm{After}$ delivery, the material was annealed for $1 \mathrm{~h}$ at $1000{ }^{\circ} \mathrm{C}$ for degassing [35]. Afterwards, smaller samples of $2 \times 2 \mathrm{~cm}^{2}$ were cut and also annealed at $1400{ }^{\circ} \mathrm{C}$ for $2 \mathrm{~h}$ to remove defects introduced during machining. After annealing, both W and W-5Ta materials were pre-thinned down to $80-100 \mu \mathrm{m}$ in thickness using $\mathrm{SiC}$ abrasive papers from grit 220 up to 4000 . TEM discs were then punched and electropolished at $-5{ }^{\circ} \mathrm{C}$ using a Struers Tenupol-5 unit and an electrolyte comprising an aqueous solution of $0.5 \mathrm{wt} . \% \mathrm{Na}_{2} \mathrm{~S}$ in the case of $\mathrm{W}$, whereas a mixture of 15 vol. $\% \mathrm{H}_{2} \mathrm{SO}_{4}(95 \%)$ and 85 vol.\% $\mathrm{CH}_{3} \mathrm{OH}$ was employed for $\mathrm{W}-5 \mathrm{Ta}$. The average grain size was $3.9 \pm 0.8 \mathrm{~mm}(\mathrm{~W})$ and $2.3 \pm 0.7 \mathrm{~mm}(\mathrm{~W}-5 \mathrm{Ta})[29,31]$.

\section{Experimental}

The samples were exposed sequentially to a $40 \mathrm{keV} \mathrm{He}{ }^{+}$beam at the temperature of $800{ }^{\circ} \mathrm{C}$, using the MIAMI-2 TEM/ion accelerator system located at the University of Huddersfield [36]. The in-situ TEM facility under ion irradiation is composed of a $300 \mathrm{kV}$ Hitachi H-9500 Transmission Electron Microscope (TEM), coupled to a $350 \mathrm{kV}$ NEC ion accelerator incorporating a Danfysik $921 \mathrm{~A}$ ion source. The ion beam is incident on the sample at an angle of $18.7^{\circ}$ to the electron beam in the TEM. Sample heating was achieved by a double-tilt heating holder (Gatan Model 652) that uses a current flow through a Ta furnace surrounding the sample. The temperature was measured via a thermocouple attached to the furnace. The sample was held in place using a Hexring® clamping mechanism to ensure good thermal contact between the sample and the furnace. On reaching the target temperature, the sample was irradiated by the $\mathrm{He}^{+}$beam in a series of steps from the lowest 
damage level of $0.004 \mathrm{dpa}$ up to $1 \mathrm{dpa}$ at a rate of $4.5 \times 10^{-4} \mathrm{dpa} / \mathrm{s}$, corresponding to a $\mathrm{He}^{+}$ fluence of $3.3 \times 10^{14}$ and $7.3 \times 10^{16} \mathrm{He}^{+} / \mathrm{cm}^{2}$ respectively.

The simulated damage profile and the Helium concentration profile (Fig.1) were calculated using the Stopping and Range of Ions in Matter (SRIM-13) software with the quick Kinchin-Pease approach [37-39], using an average displacement energy of $90 \mathrm{eV}$ [40] and default values for other software settings. The total current deposited on the sample was $0.09 \mathrm{nA}$, with a $\mathrm{He}^{+}$flux of $3.3 \times 10^{13}$ ions $/ \mathrm{cm}^{2} / \mathrm{s}$. It was predicted that over $50 \%$ of helium ions was transmitted through the foil, and $32 \%$ was implanted. The damage level was estimated as the average value in the foil thickness of $\sim 100 \pm 10 \% \mathrm{~nm}$, as determined by Convergent Electron Beam Diffraction (CBED) prior to the experiment. Micrographs were recorded along the zone axes $<001>$ and $<111>$ during the stepwise increase in He fluence, starting at the lowest damage level of only $0.004 \mathrm{dpa}$. At damage steps representative of the microstructure evolution, a through-focal series of micrographs was taken with a defocus value $\Delta f \leq 1 \mu \mathrm{m}$ in order to assess the presence of He bubbles $\geq 1 \mathrm{~nm}$ in diameter, based on the "out-of-focus" Fresnel imaging technique [41].

\section{Helium bubble detection}

In order to determine the number and size of the bubbles in the image, the topologically structured contour detection algorithm was applied from [42] as implemented in the OpenCV Library [43]. Furthermore, a graphical user interface was developed in C++ using Qt Creator as a software development kit. The methodology for detection consisted of three steps: generation of a binary image, contour estimation and area calculation.

The original TEM micrograph taken in under-focus condition was processed first using Adobe Photoshop to enhance the bubbles out of the background via adjusting the brightness and shadows and making small adjustments to individual colours with the hue and saturation layers. Then determination of relative occupations of the surface by the helium 
bubbles was specified after choosing suitable thresholds in ImageJ, version 1.53a [44]. In order to generate the binary image, the thresholded image was converted to grayscale (singlechannel conversion). This followed by a fixed-level thresholding to determine whether a pixel is black or white, thus resulting in a binary representation of the image. The contour estimation algorithm provided a set of connecting pixels, contours, at the edges of the bubbles. The area of each contour was calculated using the Green's Theorem. Additionally, the centroid of each bubble was obtained by computing the image moment of its contour, this allowed to extract the area and centroid of each bubble, giving a full description of the location and size distribution of the bubbles in the micrograph. The images obtained at each of the main steps of bubble detection are shown in Fig. 2.

\section{Results}

Fig. 3 shows the evolution of the $\mathrm{W}$ microstructure at $800^{\circ} \mathrm{C}$ as a function of damage level in the range of 0.01 up to $1 \mathrm{dpa}$, whereas the early stages of damage between 0.004 and 0.016 dpa are shown in Fig. 4. Comparatively, Fig. 5 shows the radiation-induced damage in $\mathrm{W}-5 \mathrm{Ta}$ in the same damage range as in $\mathrm{W}$ in Fig. 3. In both materials, the damaged structure is characterised by a population of helium bubbles that change in density, size and morphology with increasing damage level up to the maximum value of $1 \mathrm{dpa}$ in this work. Fig. 6 displays the evolution of the average bubble size and the number density as it relates to damage level in both materials. The radiation-induced dislocation loops were not detected in any of these materials at $800{ }^{\circ} \mathrm{C}$. A significant number of spherical bubbles of $>1 \mathrm{~nm}$ in diameter are already present in $\mathrm{W}$ at the relatively low damage level of $0.004 \mathrm{dpa}$, which corresponds to a $\mathrm{He}^{+}$fluence of $3.3 \times 10^{14} \mathrm{He}^{+} / \mathrm{cm}^{2}$. Both the average bubble size and density increase continuously up to a damage level of $0.2 \mathrm{dpa}$, where the average size reaches $\sim 3 \mathrm{~nm}$ and the density amounts to $\sim 26 \times 10^{22} / \mathrm{m}^{3}$. At higher damage levels, both the average size and density continue increasing but at a lower rate, and do not reach saturation at the end of the 
experiment. At the maximum damage level of $1 \mathrm{dpa}$, the average size of the bubble population is $3.9(3) \mathrm{nm}$ and the density is $\sim 32 \times 10^{22} / \mathrm{m}^{3}$. Additionally, at damage levels $\geq 0.3$ dpa, the He bubbles gradually change their morphology from spherical to faceted (see insets in Fig. 3 and Fig. 7a). In contrast, there are no visible bubbles in W-5Ta below 0.02 dpa, and the bubble density remains low up to $0.1 \mathrm{dpa}$. Between 0.1 and $0.2 \mathrm{dpa}$, there is a sharp increase in bubble density. At $>0.2$ dpa the density continues to rise at a lower rate than before but still higher than in $\mathrm{W}$ and reaches a value of $\sim 31 \times 10^{22} / \mathrm{m}^{3}$, which is close to the bubble density in $\mathrm{W}$ at the same damage level. Additionally, the average bubble size in W-5Ta undergoes a smaller increase with damage level and seems to saturate at 2.2(3) $\mathrm{nm}$ at $1 \mathrm{dpa}$. That size value is $\sim 1.7$ times smaller than the value measured in $\mathrm{W}$ also at $1 \mathrm{dpa}$. At such damage level, most of the He bubbles in W-5Ta still remain largely spherical (see Fig. 7b). Figure 8 plots the size frequency distribution of helium bubbles showing an increase in size as a function of a damage level up to $1 \mathrm{dpa}$. The histograms reveal a shift in bubble sizes limited to a maximum of $<3.5 \mathrm{~nm}$ and a peak frequency at $<2.5 \mathrm{~nm}$ in $\mathrm{W}-5 \mathrm{Ta}$ and a maximum of $<5 \mathrm{~nm}$ and a peak frequency at $<4 \mathrm{~nm}$ in $\mathrm{W}$ at $1 \mathrm{dpa}$.

\section{Discussion}

The helium irradiated microstructure of $\mathrm{W}$ at $800{ }^{\circ} \mathrm{C}$ is characterised by the presence of a relatively large number of bubbles, whose average size and bubble density change with an increase of a damage level, and addition of Ta content. There was no evidence of dislocation loops at $800{ }^{\circ} \mathrm{C}$. This is supported with data on tungsten-rhenium alloys irradiated with neutrons and tungsten-tantalum alloys irradiated with protons at temperatures up to $800{ }^{\circ} \mathrm{C}[29,45]$. The interstitial dislocation loops would be unstable at this elevated temperature and emit self-interstitial atoms, or glide to the free sample surface. Whereas, tungsten sample irradiated with neutrons at $\mathrm{T}<750{ }^{\circ} \mathrm{C}$ and a damage level of $<1$ dpa are characterised by the presence of dislocation loops, whereas at higher irradiation temperatures 
the irradiated microstructure is dominated by the presence of nm-sized voids and the absence of loops [46]. Generally, both W and W-Ta exhibit microstructures with $\leq 20 \%$ of the area occupied by the radiation-induced bubbles under $40 \mathrm{keV} \mathrm{He}^{+}$exposure up to $1 \mathrm{dpa}$. The helium fluence was reported to exhibit a very limited impact on bubble size in $\mathrm{W}$ at $\mathrm{T}<1200^{\circ} \mathrm{C}$. In tungsten irradiated at $800^{\circ} \mathrm{C}$ by $10 \mathrm{keV}$ helium ions, the average bubble density was found to be around $(3.0-4.0) \times 10^{16} \mathrm{~m}^{-2}$, and the mean bubble size was reported to be between $2.0 \mathrm{~nm}$ and $3.5 \mathrm{~nm}$ which is similar to results obtained in this work $\left(\sim 2 \times 10^{16} \mathrm{~m}^{-2}\right)$ [47].

Helium atom diffusion is the principal factor affecting the helium bubble nucleation and growth processes. Helium has an extremely low solubility and low migration energy in metals [48]. The irradiation temperature $800^{\circ} \mathrm{C}$ in this work corresponds to the annealing stage IV reported to occur in $\mathrm{W}$ between $650-1000^{\circ} \mathrm{C}$, when the radiation-induced vacancies become mobile [49]. In tungsten, substitutional helium atoms tend to form various strong complexes with vacancies, which are considered as the nuclei of the helium bubbles, which preferentially grow by further helium and helium-vacancy absorption [50]. DFT calculations showed that helium will migrate to vacancies rather than remain in interstitial or substitutional sites [51]. Helium atoms are strongly bound with the vacancies because they compensate its negative volume dilatation [52]. The energy barrier was estimated and reported to be quite high $(2.8 \mathrm{eV})$ for a possibility of a direct jump of the He atom from one vacancy to another in $\mathrm{W}$, supposing a great trapping effect between $\mathrm{He}$ and the vacancy in $\mathrm{W}$ [53]. At temperatures $>600^{\circ} \mathrm{C}$ mobility of the He vacancy complexes is reported to increase, which leads to the development of larger (greater than several nanometres) bubbles [54]. Ultimately these implanted $\mathrm{He}$ atoms that are trapped at vacancies may cause helium embrittlement of the material. 
Diffusion in an alloy is more complex than in a single element component where vacancy-helium atom clustering might be retarded due to the existence of solute dopants. The first-principle calculations revealed a repulsive Ta solute-vacancy interaction in $\mathrm{W}$ with a binding energy between $\mathrm{Ta}$ and a monovacancy from -0.1 to $-0.3 \mathrm{eV}$ for the first-to-third nearest-neighbour positions. However, a weak attractive interaction was reported for Ta atom on the neighbouring position perpendicular to the $<111>$ crowdion, resulting in the impeded diffusion of the SIA [55]. Therefore, the solute Ta partly increases the recombination of vacancy with interstitial, and decreases the concentration of point defects, thereby, leading to a reduced vacancy concentration within the matrix. Moreover, the binding energy between a Ta interstitial atom and a $\mathrm{He}$ atom in $\mathrm{W}$, when He was initially situated in the third to first nearest-neighbour sites relatively to a $\mathrm{Ta}$ atom, was reported to be $0.1-0.3 \mathrm{eV}$, and the binding energy between the second introduced $\mathrm{He}$ atom and existing He-Ta complex was declared to be $1.1 \mathrm{eV}$. This indicates a strong favourable binding effect and consequent trapping of $\mathrm{He}$ by substitutional $\mathrm{Ta}$ or already formed $\mathrm{He}-\mathrm{Ta}$ complexes preventing $\mathrm{He}$ atom migration in the $\mathrm{W}$ lattice [56]. The consequence of the described above events is a lower probability of interaction between vacancies and He atoms in the vicinity of tantalum atoms.

In addition, the formation energy of a mono-vacancy for the first-to-fourth nearestneighbour positions in W-5Ta alloy was reported to be higher compared to the pure tungsten, suggesting that mono-vacancies are not that easily formed around the Ta atom in $\mathrm{W}$ [57]. delaying vacancy diffusion via a solute drag effect [58], which may retard the vacancy mobility and further binding of a vacancy with $\mathrm{He}$ in W. The formation energy of a $\mathrm{He}$ interstitial in the W-5Ta alloy, with the most stable configuration for He in the substitution site, was reported to be lower $(4.56 \mathrm{eV})$ and therefore more favourable compared to the pure tungsten system $(4.92 \mathrm{eV})$ [59]. The formation energies of the He atom in the tetrahedral interstitial site and octahedral interstitial site were also calculated in pure $\mathrm{W}$ and were 
reported to be 6.18 and $6.43 \mathrm{eV}$ which is also higher than in W-Ta alloy (5.50 and $5.84 \mathrm{eV}$ respectively). The helium-vacancy clustering and the ability of bubble formation and their further growth is therefore retarded in the W-Ta system below 0.02 dpa. Whereas in contrast, already at a damage level of $0.004 \mathrm{dpa}$, small bubbles of $>1 \mathrm{~nm}$ have been detected in $\mathrm{W}$ yielding the density of $4.2 \times 10^{20} \mathrm{~m}^{-3}$. Hence, the presence of Ta interferes with helium/vacancy clustering and subsequently delays bubble nucleation causing deceleration of the bubble transition into faceted shape at higher damage levels.

A similar trend in the radiation-induced defect retention was observed in $\mathrm{W}-5 \mathrm{Ta}$ irradiated in-situ by $40 \mathrm{keV}$ protons at $800^{\circ} \mathrm{C}[29,60]$. In comparison with the growing number of voids in $\mathrm{W}$, the voids in $\mathrm{W}-5 \mathrm{Ta}$ were not detected up to a damage level of $0.3 \mathrm{dpa}$, however, the proton irradiation-induced voids became visible when the same sample was post-irradiation annealed at $1000{ }^{\circ} \mathrm{C}$, with a relatively low void density of $4.9 \pm 1.4 \times$ $10^{21} \mathrm{~m}^{-3}$ and an average size of $4.9 \pm 1.4 \mathrm{~nm}$, occurring as a result of the agglomeration of voids by a thermally activated process [29]. And the exposure of W-5Ta to a lower energy of $100 \mathrm{eV} \mathrm{He}{ }^{+}$ions showed similar behaviour with surface fuzz, a result of defect mobility being supressed in comparison to unalloyed $\mathrm{W}$ due to the bigger lattice spacing forced by doping of $\mathrm{W}$ with $\mathrm{Ta}[33,61]$. The higher fluence threshold for the formation of surface nano-structuring implies that the W-Ta alloy's surface thermal conductivity will degrade at a slower rate compared to the pure $\mathrm{W}$ system during the lifespan of a reactor [62].

The surface effect needs to be taken into account during the in-situ irradiations, especially when the TEM foil thickness is $<100 \mathrm{~nm}$ [63]. The free surface effect was previously observed on the dislocation structure due to the thin foil in the in-situ experiment [31].The ex-situ TEM analysis revealed the coexistence of dislocation tangles and loops in both materials, as opposed to the lack of dislocation tangles in the in-situ specimens. Furthermore there was no change in the nature (i.e. interstitial to vacancy type) of the 
dislocation loops and their Burgers vector, and a significant number of vacancy clusters was also not present, but we did observe the appearance of dislocation tangles in the ex-situ samples. The ex-situ irradiation of bulk tungsten with $\mathrm{He}$ ions of $400 \mathrm{keV}$ showed the formation of larger bubble diameters $(>10 \mathrm{~nm})$ but lower areal bubble density $\left(\sim 10^{16}\right.$ bubbles $\left./ \mathrm{m}^{2}\right)$ compared to the in-situ experiments. This was due to higher amounts of He retained in the irradiated bulk materials while in the in-situ experiments on thin foils some may escape due to the proximity of surfaces [64]. In addition, at higher irradiation temperature the diffusivity ratio of point defect is greater [63]. Hence, considering the influence of the surface effect, the population of the helium bubbles measured in the thin TEM foils is lower than the actual value in bulk would be.

At a damage level $\geq 0.3 \mathrm{dpa}$, the bubbles present in $\mathrm{W}$ develop energetically favourable facets with the facet planes of $\{110\}$, as interpreted by the anisotropy of the surface energy and by the preferential adsorption of diffusing helium ions on specific plane orientations with respect to the bubble surface. The descending order of surface energies in bcc is for low-index planes $\{111\},\{100\}$, and $\{110\}$ with the lowest surface energy for the planes $\{110\}$ due to the greater planar density [65]. To minimize the total free energy, the facets with the lowest surface energy occupy most of the bubble surface along $\{110\}$. The fraction of the faceted bubbles in $\mathrm{W}$ rises and amounts to $>80 \%$ at a maximum of $1 \mathrm{dpa}$. However, the spherical-to-faceted transition of bubble shape is clearly supressed in W-5Ta alloy.

\section{Conclusions}

In-situ analysis of helium bubble formation has been performed in $\mathrm{W}$ and $\mathrm{W}-5 \mathrm{Ta}$ alloy, caused by $40 \mathrm{keV} \mathrm{He}^{+}$irradiation at $800^{\circ} \mathrm{C}$ up to 1 dpa with a maximum He-to-dpa ratio of 5.5 at $\% / d p a$. The extensive use of advanced in-situ TEM characterizations showed the effect of helium fluence and alloying component on the structural morphology of the 
helium bubbles. The spherical bubbles of $>1 \mathrm{~nm}$ were observed in $\mathrm{W}$ at the relatively low damage level of $0.004 \mathrm{dpa}$, which corresponds to a $\mathrm{He}^{+}$fluence of $3.3 \times 10^{14} \mathrm{He}^{+} / \mathrm{cm}^{2}$. The presence of only $5 \mathrm{wt} . \% \mathrm{Ta}$ in solid solution impedes the diffusion of helium ions at $800{ }^{\circ} \mathrm{C}$ and interferes with the binding of He ions with vacancies into complexes, which serve as the core of a helium bubble, and therefore hinders the nucleation of the bubbles $<0.02 \mathrm{dpa}$. Moreover, at $1 \mathrm{dpa},>80 \%$ of the bubbles in $\mathrm{W}$ steadily develops facets, whereas in contrast in W-5Ta bubbles still present a spherical shape.

\section{Acknowledgements}

The authors of this work acknowledge Prof S. E. Donnelly for access to the MIAMI-2 facility (grant ref. EPSRC EP/M028283/1) through the EPSRC funded mid-range facility, the UK National Ion Beam Centre (NS/A000059/1). Authors I.I., M.J.D.R. and S.C.M. are supported through the Sêr Cymru Nuclear Futures Institute funded through WEFO (Wales).

\section{References}

[1] V. Philipps, Tungsten as material for plasma-facing components in fusion devices, J. Nucl. Mater. 2011, 415, S2-S9.

[2] D. Stork, P. Agostini, J.L. Boutard, D. Buckthorpe, E. Diegele, S.L. Dudarev, et al., Developing structural, high-heat flux and plasma facing materials for a near-term DEMO fusion power plant: The EU assessment, J. Nucl. Mater. 2014, 455, 277-291.

[3] T. Hirai, S. Panayotis, V. Barabash, C. Amzallag, F. Escourbiac, A. Durocher, et al., Use of tungsten material for the ITER divertor, Nucl. Mater. Ener. 2016, 9, 616-622.

[4] V. A. Soukhanovskii, A review of radiative detachment studies in tokamak advanced magnetic divertor configurations, Plasma Phys. Control. Fusion. 2017, 59, 064005.

[5] Y. Ueda, J.W. Coenen, G. De Temmerman, R.P. Doerner, J. Linke, V. Philipps, E. Tsitrone, Research status and issues of tungsten plasma facing materials for ITER and beyond, Fusion Eng. Des. 2014, 89, 901-906. 
[6] R. Villari, V. Barabash, F. Escourbiac, L. Ferrand, T. Hirai, V. Komarov, et al., Nuclear analysis of the ITER full-tungsten divertor, Fusion Eng. Des. 2013, 88, 2006-2010.

[7] F. Crescenzia, C. Bachmann, M. Richou, S. Roccella, E. Visca, J.-H. You, Design study of ITER-like divertor target for DEMO, Fusion Eng. Des. 2015, 98-99, 1263-1266.

[8] H. Reimerdes, R. Ambrosino, P. Innocente, A. Castaldo, P. Chmielewski, G. Di Gironimo, et al., Assessment of alternative divertor configurations as an exhaust solution for DEMO, Nucl. Fusion. 2020, 60, 066030.

[9] S. Heuer, Th Weber, G. Pintsuk, J.W. Coenen, J. Matejicek, Ch Linsmeier, Aiming at understanding thermo-mechanical loads in the first wall of DEMO: stress-strain evolution in a Eurofer-tungsten test component featuring a functionally graded interlayer, Fusion Eng. Des. 2018, 135, 141-153.

[10] T.R. Barrett, G. Ellwood, G. Pérez, M. Kovari, M. Fursdon, F. Domptail, t al., Progress in the engineering design and assessment of the European DEMO first wall and divertor plasma facing components, Fusion Eng. Des. 2016, 109-111, 917-924.

[11] P. Sardain, B. Michel, L. Giancarli, A. Li Puma, Y. Poitevin, J. Szczepanski, et al. Fusion Eng. Des. 2003, 69, 769-774.

[12] M. Rieth, S.L. Dudarev, S.M. Gonzalez de Vicente, J. Aktaa, T. Ahlgren, S. Antusch, et al., J. Nucl. Mater. 2013, 442, S173-S180.

[13] M. Barbarino, A. Leonard, N.N. Asakura, M. Jakubowski, M. Kobayashi, B. Lipschutz, et al., Summary of the 3rd IAEA technical meeting on divertor concepts, Nucl. Fusion (In Press).

[14] T. Shen, Y. Dai, Y. Lee, Microstructure and tensile properties of tungsten at elevated temperatures, J. Nucl. Mater. 2016, 468, 348-354.

[15] P. Gumbsch, Brittle fracture and the brittle-to-ductile transition of tungsten, J. Nucl. Mater. 2003, 323, 304-312. 
[16] B. Gludovatz, S. Wurster, A. Hoffmann, R. Pippan, Fracture toughness of polycrystalline tungsten alloys, Int. J. Refract. Metals Hard Mater. 2010, 28, 674-678.

[17] E. Gaganidze, D. Rupp, J. Aktaa, Fracture behaviour of polycrystalline tungsten, J. Nucl. Mater. 2014, 446, 240-245.

[18] H. Bolt, V. Barabash, G. Federici, J. Linke, A. Loarte, J. Roth, K. Sato, Plasma facing and high heat flux materials - Needs for ITER and beyond, J. Nucl. Mater. 2002, 307-311, 43-52.

[19] I.V. Gorynin, V.A. Ignatov, V.V. Rybin, S.A. Fabritsiev, V.A. Kazakov, V.P. Chakin, et al., Effects of neutron irradiation on properties of refractory metals, J. Nucl. Mater. 1992, 191-194, 421-425.

[20] S.J. Zinkle, N.M. Ghoniem, Operating temperature windows for fusion reactor structural Materials, Fusion Eng. Des. 2000, 51-52, 55-71.

[21] N. Baluc, Materials for fusion power reactors, Plasma Phys. Control. Fusion 2006, 48, B165-B177.

[22] N. Yoshida, Review of recent works in development and evaluation of high-Z plasma facing materials, J. Nucl. Mater. 1999, 266-269, 197-206.

[23] M.J. Baldwin, R.P. Doerner, Formation of helium induced nanostructure "fuzz" on various tungsten grades, $J$. Nucl. Mater. 2010, 404, 165.

[24] S. Kajita, W. Sakaguchi, N. Ohno, N. Yoshida, T. Saeki, Formation process of tungsten nanostructure by the exposure to helium plasma under fusion relevant plasma conditions, Nucl. Fusion 2009, 49, 095005.

[25] M. Rieth, S.L. Dudarev, S.M. Gonzalez de Vicente, J. Aktaa, T. Ahlgren, S. Antusch, et al., A brief summary of the progress on the EFDA tungsten materials program, J. Nucl. Mater. 2013, 442, S173-S180. 
[26] E.Tejado, P.A.Carvalho, A.Muñoz, M.Dias, J.B.Correia, U.V.Mardolcar, J.Y.Pastor, The effects of tantalum addition on the microtexture and mechanical behaviour of tungsten for ITER applications, J. Nucl. Mater. 2015, 467, 949.

[27] D. Jiang, Q. Wang, W. Hu, Z. Wei, J. Tong, H. Wan, The effect of tantalum (Ta) doping on mechanical properties of tungsten (W): a first-principles study, J. Mater. Res. 2016, 31, $3401-3408$

[28] Z. Wang, Y. Yuan, K. Arshad, J. Wang, Z. Zhou, J. Tang, G.-H. Lu, Effects of tantalum concentration on the microstructures and mechanical properties of tungsten-tantalum alloys, Fusion Eng. Des. 2017, 125, 496-502.

[29] I. Ipatova I, R.W. Harrison, S.E. Donnelly, M.J.D. Rushton, S.C. Middleburgh, E. Jimenez-Melero, Void evolution in tungsten and tungsten-5wt.\% tantalum under in-situ proton irradiation at 800 and $1000^{\circ} \mathrm{C}, \mathrm{J} . \mathrm{Nucl}$. Mater. 2019, 526, 151730.

[30] X. Yi, M.L. Jenkins, K. Hattar, P.D. Edmondson, S.G. Roberts, Characterisation of radiation damage in $\mathrm{W}$ and $\mathrm{W}$-based alloys from $2 \mathrm{MeV}$ self-ion near-bulk implantations, Acta Mater. 2015, 92, 163.

[31] I. Ipatova, R.W. Harrison, P.T. Wady, S.M. Shubeita, D. Terentyev, S.E. Donnelly, E. Jimenez-Melero, Structural defect accumulation in tungsten and tungsten-5wt.\% tantalum under incremental proton damage, J. Nucl. Mater. 2018, 501, 329.

[32] H. Zhou, J. Yu, W. Han, L. Cheng, C. Chen, K. Zhu, Large plastic deformation blistering and helium retention in 5\% tantalum doped tungsten under $60 \mathrm{keV}$ helium ions implantation, Fus. Eng. Des. 2018, 134, 43-50.

[33] S. Gonderman, J.K. Tripathi, T. Sizyuk, A. Hassanein, Suppression of surface microstructure evolution in $\mathrm{W}$ and $\mathrm{W}-\mathrm{Ta}$ alloys during simultaneous and sequential He and D ion irradiation in fusion relevant conditions, Nucl. Fusion. 2017, 57, 086001. 
[34] J. Linke, T. Loewenhoff, V. Massaut, G. Pintsuk, G. Ritz, M. Rödig, et al., Performance of different tungsten grades under transient thermal loads, Nucl. Fusion. 2011, 51, 073017.

[35] Y. Zayachuk, M.H.J. t Hoen, P.A. Zeijlmans van Emmichoven, D. Terentyev, I. Uytdenhouwen, G. van Oost, Surface modification of tungsten and tungsten-tantalum alloys exposed to high-flux deuterium plasma and its impact on deuterium retention, Nucl. Fusion. 2013, 53, 013013.

[36] G. Greaves, A.H. Mir, R.W. Harrison, M.A. Tunes, S.E. Donnelly, J.A. Hinks, New Microscope and Ion Accelerators for Materials Investigations (MIAMI-2) system at the University of Huddersfield, Nucl. Instr. Meth. Phys. Res. A. 2019, 931, 37-43.

[37] J.F. Ziegler, Stopping of energetic light ions in elemental matter, J. Appl. Phys. 1999, 85, $1249-1272$.

[38] J.F. Ziegler, M.D. Ziegler, J.P. Biersack, SRIM e the stopping and range of ions in matter (2010), Nucl. Instrum. Methods Phys. Res. B. 2010, 268, 1818-1823.

[39] R.E. Stoller, M.B. Toloczko, G.S. Was, A.G. Certain, S. Dwaraknath, F.A. Garner. On the use of SRIM for computing radiation damage exposure. Nucl. Instr. Meth. Phys. Res. B. 2013, 310, 75-80.

[40] ASTM E521-96, Standard Practice for Neutron Radiation Damage Simulation by Charged-Particle Irradiation, 2009.

[41] M.L. Jenkins, M.A. Kirk, Characterization of Radiation Damage by Transmission Electron Microscopy, IOP Publishing Ltd. 2001.

[42] S. Suzuki, K. Abe, Topological structural analysis of digitized binary images by border following, Computer Vision, Graphics, and Image Processing. 1985, 30, 32-46

[43] G. Bradski, The OpenCV Library, Dr. Dobb's Journal of Software Tools. 2000.

[44] C.A. Schneider, W.S. Rasband, K.W. Eliceiri, NIH Image to ImageJ: 25 years of image analysis. Nat. Methods. 2012, 9, 671-675. 
[45] M. Fukuda, K. Yabuuchi, S. Nogami, A. Hasegawa, T. Tanaka, Microstructural development of tungsten and tungsten-rhenium alloys due to neutron irradiation in HFIR, J. Nucl. Mater. 455 (2014) 460-463.

[46] A. Hasegawa, M. Fukuda, S. Nogami, K. Yabuuchi, Neutron irradiation effects on tungsten materials, Fusion Eng. Des. 89 (2014) 1568-1572

[47] X. Yi, K. Arakawa, D. Nguyen-Manh, F. Ferroni, P. Liu, W. Han, et al., A study of helium bubble production in $10 \mathrm{keV} \mathrm{He}+$ irradiated tungsten. Fus. Eng. Des. 2017, 125, 454457.

[48] H. Iwakiri, K. Yasunaga, K. Morishita, and N. Yoshida, Microstructure evolution in tungsten during low-energy helium ion irradiation, J. Nucl. Mater. 2000, 283-287, 11341138.

[49] L.K. Keys, J. Moteff, Neutron irradiation and defect recovery of tungsten, J. Nucl. Mater. 1970, 34, 260-280.

[50] X.C. Li, Y.-N, Li,Y. Yu, G.-N. Luo, X. Shu, G.-H. Lu, Helium defects interactions and mechanism of helium bubble growth in tungsten: A molecular dynamics simulation, $J$. Nucl. Mater. 2014, 451, 356-360.

[51] S.-C. Lee, J.-H. Choi, J. G. Lee, Energetics of He and H atoms with vacancies in tungsten: First-principles approach, J. Nucl. Mater. 2009, 383(3), 244-246.

[52] G. D. Samolyuk,Y. N. Osetsky \&R. E. Stoller, Properties of Vacancy Complexes with Hydrogen and Helium Atoms in Tungsten from First Principles, Fusion Sc. Technol. 2017, 71, 52-59.

[53] C. González and R. Iglesias, "Migration mechanisms of helium in copper and tungsten," J. Mater. Sci., vol. 49, no. 23, pp. 8127-8139, 2014. 
[54] Y. Ueda, J.W. Coenen, G. De Temmerman, R.P. Doerner, J. Linke, V. Philipps, et al., Research status and issues of tungsten plasma facing materials for ITER and beyond. Fus. Eng. Des. 2014, 89, 901-906.

[55] X.-S. Kong, X. Wu, Y.-W. You, C.S. Liu, Q.F. Fang, J.-L. Chen et al., First-principles calculations of transition metal-solute interactions with point defects in tungsten. Acta Mater. 2014, 66, 172-183.

[56] X. Wu, X.-S. Kong, Y.-W. You, C.S. Liu, Q.F. Fang, J.-L. Chen et al., Effects of alloying and transmutation impurities on stability and mobility of helium in tungsten under a fusion environment. Nucl. Fusion. 2013, 53, 073049-073058.

[57] S. Wen, K. Hu, M.Pan et al., Effect of transmutation elements Re and Ta on the vacancy formation anddissociation behaviors in W bulk. Comput. Mater. Sci. 2020, 179, 109624.

[58] T. Garnier, M. Nastar, P. Bellon, D.R. Trinkle, Solute drag by vacancies in bodycentered cubic alloys. Phys. Rev. 2013, B 88, 134201.

[59] C. Wan, S.Yu, X.Ju, W.Wang, Hydrogen trapping in helium-implanted W and W-Ta alloy: First-principles approach. J. Nucl. Mater. 2018, 508, 249-256.

[60] F.A. Smidt Jr., J.A. Sprague, Suppression of void nucleation by a vacancy trapping mechanism. Scripta Metall. 1973, 7, 495-501.

[61] S. Gonderman, J.K. Tripathi, T. Sizyuk, A. Hassanein, The effect of low energy helium ion irradiation on tungsten-tantalum (W-Ta) alloys under fusion relevant conditions, J. Nucl. Mater. 2017, 491, 199-205.

[62] T. Novakowski, J. Tripathi, A. Hassanein. Effect of high-flux, low-energy He+ ion irradiation on Ta as a plasma-facing material, Sci. Rep. 2016, 6, 39746.

[63] Y. Li, L. Wang, Y.Yuan, et al, In-situ TEM investigation of $30 \mathrm{keV}$ he+ irradiated tungsten: Effects of temperature, fluence, and sample thickness on dislocation loop evolution, Acta Mater. 2021, 206, 116618. 
[64] R.W. Harrison, N. Peng, R.P. Webb, et al, Characterisation of helium ion irradiated bulk tungsten: A comparison with the in-situ TEM technique, Fusion Eng. Des. 2019, 138, 210216.

[65] E. Aghemenloh, J.O. Umukoro, S.O. Azi, S. Yusuf, J.O.A. Idiodi, Surface energy calculation of bcc metals using the analytical equivalent crystal theory method, J. Nucl. Mater. 2011, 50, 3290-3296.

\section{Figure captions}

Fig. 1. Simulated damage and $\mathrm{He}^{+}$concentration profiles in $\mathrm{W}$ at a damage level of 1 dpa to a He-to-dpa ratio of 5.5 at $\% / d p a$, using the SRIM software with the quick Kinchin-Pease approach and the total current deposited on the sample in the experiment of $0.09 \mathrm{nA}$. The damage level was estimated at each step in the microstructure evolution as the average value in the foil thickness of $\sim 100 \mathrm{~nm}$. According to SRIM calculations, $32 \%$ of the $40 \mathrm{keV}$ He ions was implanted and 56\% was transmitted through the foil.

Fig. 2. A series of images of helium bubbles observed in $\mathrm{W}$ at $800{ }^{\circ} \mathrm{C}$ and a damage level of 1 dpa through the main steps of the bubble detection: (a) bright-field image in under-focus condition, (b) thresholded image with enhanced bubbles, (c) grayscale binary image, (d) estimated contoured areas of detected bubbles

Fig. 3. In-situ observation of the bubble evolution $\mathrm{W}$ at $800{ }^{\circ} \mathrm{C}$ at selected damage levels up to $1 \mathrm{dpa}$ induced by a $40 \mathrm{keV} \mathrm{He}$ ion beam: (a) $0.01 \mathrm{dpa}$, (b) $0.02 \mathrm{dpa}$, (c) $0.05 \mathrm{dpa}$, (d) 0.075 dpa, (e) $0.1 \mathrm{dpa}$, (f) $0.2 \mathrm{dpa}$, (g) $0.3 \mathrm{dpa}$, (h) $0.4 \mathrm{dpa}$, (i) $0.75 \mathrm{dpa}$, (j) $1 \mathrm{dpa}$. The insets show the bubble transition from spherical to faceted at $\geq 0.3 \mathrm{dpa}$. The TEM foil thickness was derived by way of the graphical method from the spacing of the fringes of the CBED patterns and was measured to be $\sim 100 \mathrm{~nm} \pm 10 \%$ 
Fig. 4. In-situ observation of bubble formation in $\mathrm{W}$ at $800{ }^{\circ} \mathrm{C}$ caused by a $40 \mathrm{keV} \mathrm{He}^{+}$ion beam at the relatively low damage levels of: (a) $0.004 \mathrm{dpa}$, (b) $0.008 \mathrm{dpa}$, (c) $0.016 \mathrm{dpa}$. The TEM foil thickness was derived by way of the graphical method from the spacing of the fringes of the CBED patterns and was measured to be $\sim 100 \mathrm{~nm} \pm 10 \%$

Fig. 5. In-situ observation of the bubble evolution $\mathrm{W}-5 \mathrm{Ta}$ at $800^{\circ} \mathrm{C}$ at selected damage levels up to $1 \mathrm{dpa}$ induced by a $40 \mathrm{keV} \mathrm{He}{ }^{+}$ion beam: (a) $0.01 \mathrm{dpa}$, (b) $0.02 \mathrm{dpa}$, (c) $0.04 \mathrm{dpa}$, (d) $0.05 \mathrm{dpa}$, (e) $0.1 \mathrm{dpa}$, (f) $0.2 \mathrm{dpa}$, (g) $0.3 \mathrm{dpa}$, (h) $0.4 \mathrm{dpa}$, (i) $0.75 \mathrm{dpa}$, (j) $1 \mathrm{dpa}$

Fig. 6. Average bubble size and bubble density in $\mathrm{W}$ and $\mathrm{W}-5 \mathrm{Ta}$ alloy at $800{ }^{\circ} \mathrm{C}$ as a function of damage level

Fig. 7. Bright field TEM image of spherical bubbles in W-5Ta and faceted bubbles in W, at $800{ }^{\circ} \mathrm{C}$ and the damage level of $1 \mathrm{dpa}$ induced by a $40 \mathrm{keV} \mathrm{He}{ }^{+}$ion beam. The insets show the electron diffraction patterns taken along the zone axis $<001>$ and $<111>$

Fig. 8 Frequency distribution histograms of helium bubble size showing an increase in size as a function of a damage level in $\mathrm{W}$ and $\mathrm{W}-5 \mathrm{Ta}$ irradiated with $40 \mathrm{keV} \mathrm{He}$ ions to a Heappm/dpa ratio of 55,000 and dose of $1 \mathrm{dpa}$ 


\section{In-situ TEM investigation of nano-scale helium bubble evolution in tantalum-doped tungsten at $800{ }^{\circ} \mathrm{C}$}

I. Ipatova $^{\mathrm{a}^{*}}$, G. Greaves ${ }^{\mathrm{b}}$, S. Pacheco-Gutiérrez ${ }^{\mathrm{c}}$, S.C. Middleburgh ${ }^{\mathrm{a}}$, M.J.D. Rushton ${ }^{\mathrm{a}}$, E. Jimenez-Melero ${ }^{\mathrm{d}}$

${ }^{a}$ Nuclear Fututres institute, Bangor University, Dean Street, Bangor Gwynedd, LL57 1 UT, UK

${ }^{b}$ School of Computing and Engineering, University of Huddersfield, Huddersfield, HD1 3DH, UK

${ }^{c} U K A E A$ - RACE, Culham Science Centre, Abingdon, OX14 3DB, UK

${ }^{d}$ Materials Performance Centre, Department of Materials, The University of Manchester, Manchester M13 9PL, UK

\section{Corresponding author $(*)$ :}

Nuclear Futures Institute

Bangor University

Dean Street

Bangor Gwynedd

LL57 1UT

United Kingdom

Tel.: +44 7849290480

Email: i.ipatova@bangor.ac.uk 


\section{Abstract}

The aim of this work is to probe the helium induced defect production and accumulation in $40 \mathrm{keV} \mathrm{He}{ }^{+}$irradiated polycrystalline $\mathrm{W}$ and its alternative alloy $\mathrm{W}-5 \mathrm{wt} . \% \mathrm{Ta}$ using transmission electron microscopy (TEM) combined with in-situ helium irradiation at $800^{\circ} \mathrm{C}$. A maximum damage level of 1 dpa with a maximum He-to-dpa ratio of 5.5 at $\% /$ dpa has been reached in this work for both materials, which corresponds to an ion fluence of $7.33 \times 10^{16}$ $\mathrm{He}^{+} / \mathrm{cm}^{2}$. The presence of radiation-induced dislocation loops was not observed at this temperature. The low density of the incipient bubbles in $\mathrm{W}$ has been already detected at $0.004 \mathrm{dpa}$, which corresponds to a fluence of $3.3 \times 10^{14} \mathrm{He}^{+} / \mathrm{cm}^{2}$. The experiments conducted at $800{ }^{\circ} \mathrm{C}$ have shown that the addition of $5 \mathrm{wt} . \%$ of tantalum into tungsten may diminish the binding of He ions with vacancies into complexes, which serve as the core of the bubble, thus hindering helium bubble formation below $0.02 \mathrm{dpa}$ and their further growth and population at higher damage levels. By exceeding the damage dose $\geq 0.3 \mathrm{dpa}$, a progressive transition from a spherical to a faceted shape of the bubbles has been observed in $\mathrm{W}$ but not in the W-5Ta alloy. At $1 \mathrm{dpa},>80 \%$ of the bubbles in $\mathrm{W}$ were of the faceted type with the facet planes of $\{110\}$.

Keywords: W/W-5Ta; fusion materials; in-situ helium exposure; faceted helium defects; transmission electron microscopy; bubble detection. 


\section{Introduction}

Tungsten and its engineered alloys are the preferred choice as armour material for plasma-facing components (PFCs) by the nuclear fusion community, and therefore lie at the heart of the international roadmap for the realisation and deployment of fusion reactor technology $[1,2]$. In ITER, the divertor design includes $\mathrm{W}$ monoblocks in the inner and outer vertical targets in each water-cooled cassette assembly [3]. The divertor itself is intended to serve as the plasma power exhaust, particle control (deuterium/tritium (DT) and He repumping), also functioning as a screen for impurities, reducing contamination [4]. The peak power flux density values for the ITER design range from $8 \mathrm{MW} \mathrm{m}^{-2}$ at most in the nonnuclear phases $\left(\mathrm{H} / \mathrm{He}\right.$ discharges) to $10 \mathrm{MWm}^{-2}$ in the nuclear phases (DT burning discharges), corresponding to $\mathrm{W}$ surface temperatures of $\sim 800{ }^{\circ} \mathrm{C}$ and $\sim 1100{ }^{\circ} \mathrm{C}$ respectively [5]. This may increase to as much as $20 \mathrm{MWm}^{-2}$ during transient events at the monoblock surface [6]. Radiation-induced damage levels in ITER divertor monoblocks are predicted to be $\sim 0.1 \mathrm{dpa}$ after a four-year ITER nuclear operation phase, prior to cassette replacement of the first divertor, and $\sim 0.5 \mathrm{dpa}$ for permanent divertor components during ITER's end-of-life operation [6].

An ITER-like divertor design for the future fusion demonstration power plant (DEMO) is being considered [7], alongside alternative configurations able to handle the more demanding radiation environment in the inner target of the divertor [8]. Besides this, DEMO is envisaged to comprise a first wall with a $\mathrm{W}$ armour joint to a reduced-activation ferritic/martensitic (RAFM) steel [9, 10], with predicted surface heat fluxes of 0.5-1.2 $\mathrm{MWm}^{-2}[10,11]$. The expected lowest shield temperatures for $\mathrm{W}$ armour materials range from $\sim 500{ }^{\circ} \mathrm{C}$ in the first wall up to $>800-900{ }^{\circ} \mathrm{C}$ in proposed He-cooled divertor designs and $>1700{ }^{\circ} \mathrm{C}$ in the divertor armour surface [12], whereas neutron bombardment is 
estimated to cause $\sim 4$ dpa in the $\mathrm{W}$ armour at the end-of-life of $\mathrm{W}-\mathrm{Cu}$ plasma-facing components in DEMO [13].

Tungsten is characterised by a relatively low ductile-to-brittle-temperature (DBTT), namely $\sim 200-400{ }^{\circ} \mathrm{C}$ [14-17], which can increase progressively with damage level due to the radiation fields inside the fusion reactor core up to $\sim 800-1000{ }^{\circ} \mathrm{C}[18,19]$. Thermal cycling across the DBTT from temperatures between $70-120{ }^{\circ} \mathrm{C}$ up to the maximum surface temperature in $\mathrm{W}$ mock-ups during High-Heat-Flux (HHF) tests does not induce the formation of macro-cracks. However, macro-cracks are observed at a heat load of $20 \mathrm{MWm}^{-2}$ with the surface temperature approaching $2000{ }^{\circ} \mathrm{C}$ [3]. The highest temperature for safe operation of $\mathrm{W}$ components is limited by the resistance to creep, low-cycle fatigue, helium embrittlement and recrystallization $[20,21]$. Mechanical test data at $800{ }^{\circ} \mathrm{C}$ constitute a representative property database for $\mathrm{W}$ monoblocks that is compared to their performance under HHF tests and is also used as key input for the universal slope method aimed at correlating tensile properties and fatigue performance of $\mathrm{W}$ monoblocks [3]. Plasma exposure of W-based PFCs causes radiation-induced lattice damage, surface sputtering, hydrogen isotope retention and He accumulation and diffusion into the bulk structure [22]. The latter effect can lead to bubble formation and potential blistering and, as a consequence, embrittlement at low temperatures and ductility loss at high temperatures [22]. Additionally, $\mathrm{W}$ exposure to He ions in the eV energy regime $(>20-30 \mathrm{eV})$, where physical sputtering does not play a significant role in changes to surface morphology, at temperatures $>700{ }^{\circ} \mathrm{C}$ and a minimal He fluence of $\sim 10^{25} \mathrm{~m}^{-2}$ induces the formation of 'nanostructured or fuzzy $\mathrm{W}$ ' on the material surface $[5,23,24]$.

In this work we have applied extensive in-situ damage and microstructural analysis techniques to observe $\mathrm{W}$ and $\mathrm{W}-5 \mathrm{wt} . \% \mathrm{Ta}$ (W-5Ta) materials at $800{ }^{\circ} \mathrm{C}$ and exposed to 40 $\mathrm{keV} \mathrm{He}^{+}$irradiations at incremental damage levels from only $0.004 \mathrm{dpa}$ up to $1 \mathrm{dpa}$ with a 
maximum He-to-dpa ratio of 5.5 at $\% /$ dpa. Tantalum alloying is one of the proposed engineering solutions to overcome the inherent drawbacks of $\mathrm{W}$ as a structural material, since Ta is reported to shift the onset of $\mathrm{W}$ recrystallization [25-28]. It has also been shown to reduce the vacancy mobility and to consequently delay void formation at $800{ }^{\circ} \mathrm{C}$ under proton irradiation [29]. In W-5Ta, voids were not found up to a damage level of $0.3 \mathrm{dpa}$, however, the excess of free vacancies present in the $\mathrm{W}-5 \mathrm{Ta}$ irradiated at $800^{\circ} \mathrm{C}$ led to the formation of visible voids in TEM study after post-irradiation annealing of the sample at $1000{ }^{\circ} \mathrm{C}$. At lower temperatures the presence of Ta also retards the mobility of self-interstitial atoms (SIAs) and interstitial $\mathrm{a} / 2<111>$ dislocation loops under irradiation at lower temperatures, and consequently the loop growth and coalescence, attaining saturation in loop dimensions at relatively low damage levels $[30,31]$. Ta is also observed to hinder the surface blistering in $\mathrm{W}$ under high-fluence deuterium plasma irradiation [32]. In addition, dual beam and sequential irradiation experiments have shown to shift the fluence threshold for fuzz formation higher in $\mathrm{W}-\mathrm{Ta}$ alloys at $950^{\circ} \mathrm{C}$ as the ratio of $\mathrm{D}^{+} / \mathrm{He}^{+}$ions increases due to a significant D de-trapping at that temperature which led to the fast diffusion and escape of the implanted species [33]. The main research objective is to demonstrate the effect of the presence of $\mathrm{Ta}$ solute atoms in $\mathrm{W}$-Ta binary system on response to radiation under cumulative helium beam exposure at an elevated temperature of $800{ }^{\circ} \mathrm{C}$ which remains largely unexplored. The results obtained in this work are important to the fusion community helping to expand the pallet of candidate structural materials for future fusion devices that are more resistant to $\mathrm{He}+$ induced surface damage. This data will also help to validate predictive models of the expected in-service degradation of fusion construction materials, so that more advanced alloy compositions with optimised properties can be designed and developed for the fusion reactors. 


\section{Materials}

The initial $1 \mathrm{~mm}$-thick W sheet (99.95\%) was provided by Goodfellow Cambridge Ltd. The as-received $\mathrm{W}$ material was annealed in vacuum at $1400{ }^{\circ} \mathrm{C}$ for $2 \mathrm{~h}$ for recrystallization. The W-5Ta alloy was instead produced by Plansee AG via powder metallurgy. W-5Ta was double forged and then annealed at $1600{ }^{\circ} \mathrm{C}$ for $1 \mathrm{~h} \mathrm{[34].} \mathrm{After}$ delivery, the material was annealed for $1 \mathrm{~h}$ at $1000{ }^{\circ} \mathrm{C}$ for degassing [35]. Afterwards, smaller samples of $2 \times 2 \mathrm{~cm}^{2}$ were cut and also annealed at $1400{ }^{\circ} \mathrm{C}$ for $2 \mathrm{~h}$ to remove defects introduced during machining. After annealing, both $\mathrm{W}$ and $\mathrm{W}-5$ Ta materials were pre-thinned down to $80-100 \mu \mathrm{m}$ in thickness using $\mathrm{SiC}$ abrasive papers from grit 220 up to 4000. TEM discs were then punched and electropolished at $-5{ }^{\circ} \mathrm{C}$ using a Struers Tenupol-5 unit and an electrolyte comprising an aqueous solution of 0.5 wt. $\% \mathrm{Na}_{2} \mathrm{~S}$ in the case of $\mathrm{W}$, whereas a

mixture of 15 vol. $\% \mathrm{H}_{2} \mathrm{SO}_{4}(95 \%)$ and 85 vol.\% $\mathrm{CH}_{3} \mathrm{OH}$ was employed for W-5Ta. The average grain size was $3.9 \pm 0.8 \mathrm{~mm}(\mathrm{~W})$ and $2.3 \pm 0.7 \mathrm{~mm}(\mathrm{~W}-5 \mathrm{Ta})[29,31]$.

\section{Experimental}

The samples were exposed sequentially to a $40 \mathrm{keV} \mathrm{He}{ }^{+}$beam at the temperature of $800{ }^{\circ} \mathrm{C}$, using the MIAMI-2 TEM/ion accelerator system located at the University of Huddersfield [36]. The in-situ TEM facility under ion irradiation is composed of a $300 \mathrm{kV}$ Hitachi H-9500 Transmission Electron Microscope (TEM), coupled to a $350 \mathrm{kV} \mathrm{NEC} \mathrm{ion}$ accelerator incorporating a Danfysik 921A ion source. The ion beam is incident on the sample at an angle of $18.7^{\circ}$ to the electron beam in the TEM. Sample heating was achieved by a double-tilt heating holder (Gatan Model 652) that uses a current flow through a Ta furnace surrounding the sample. The temperature was measured via a thermocouple attached to the furnace. The sample was held in place using a Hexring® clamping mechanism to ensure good thermal contact between the sample and the furnace. On reaching the target temperature, the sample was irradiated by the $\mathrm{He}^{+}$beam in a series of steps from the lowest 
damage level of $0.004 \mathrm{dpa}$ up to $1 \mathrm{dpa}$ at a rate of $4.5 \times 10^{-4} \mathrm{dpa} / \mathrm{s}$, corresponding to a $\mathrm{He}^{+}$ fluence of $3.3 \times 10^{14}$ and $7.3 \times 10^{16} \mathrm{He}^{+} / \mathrm{cm}^{2}$ respectively.

The simulated damage profile and the Helium concentration profile (Fig.1) were calculated using the Stopping and Range of Ions in Matter (SRIM-13) software with the quick Kinchin-Pease approach [37-39], using an average displacement energy of $90 \mathrm{eV}$ [40] and default values for other software settings. The total current deposited on the sample was $0.09 \mathrm{nA}$, with a $\mathrm{He}^{+}$flux of $3.3 \times 10^{13}$ ions $/ \mathrm{cm}^{2} / \mathrm{s}$. It was predicted that over $50 \%$ of helium ions was transmitted through the foil, and $32 \%$ was implanted. The damage level was estimated as the average value in the foil thickness of $\sim 100 \pm 10 \% \mathrm{~nm}$, as determined by Convergent Electron Beam Diffraction (CBED) prior to the experiment. Micrographs were recorded along the zone axes $<001>$ and $<111>$ during the stepwise increase in He fluence, starting at the lowest damage level of only $0.004 \mathrm{dpa}$. At damage steps representative of the microstructure evolution, a through-focal series of micrographs was taken with a defocus value $\Delta f \leq 1 \mu \mathrm{m}$ in order to assess the presence of He bubbles $\geq 1 \mathrm{~nm}$ in diameter, based on the "out-of-focus" Fresnel imaging technique [41].

\section{Helium bubble detection}

In order to determine the number and size of the bubbles in the image, the topologically structured contour detection algorithm was applied from [42] as implemented in the OpenCV Library [43]. Furthermore, a graphical user interface was developed in C++ using Qt Creator as a software development kit. The methodology for detection consisted of three steps: generation of a binary image, contour estimation and area calculation.

The original TEM micrograph taken in under-focus condition was processed first using Adobe Photoshop to enhance the bubbles out of the background via adjusting the brightness and shadows and making small adjustments to individual colours with the hue and saturation layers. Then determination of relative occupations of the surface by the helium 
bubbles was specified after choosing suitable thresholds in ImageJ, version 1.53a [44]. In order to generate the binary image, the thresholded image was converted to grayscale (singlechannel conversion). This followed by a fixed-level thresholding to determine whether a pixel is black or white, thus resulting in a binary representation of the image. The contour estimation algorithm provided a set of connecting pixels, contours, at the edges of the bubbles. The area of each contour was calculated using the Green's Theorem. Additionally, the centroid of each bubble was obtained by computing the image moment of its contour, this allowed to extract the area and centroid of each bubble, giving a full description of the location and size distribution of the bubbles in the micrograph. The images obtained at each of the main steps of bubble detection are shown in Fig. 2.

\section{Results}

Fig. 3 shows the evolution of the $\mathrm{W}$ microstructure at $800^{\circ} \mathrm{C}$ as a function of damage level in the range of 0.01 up to $1 \mathrm{dpa}$, whereas the early stages of damage between 0.004 and 0.016 dpa are shown in Fig. 4. Comparatively, Fig. 5 shows the radiation-induced damage in $\mathrm{W}-5 \mathrm{Ta}$ in the same damage range as in $\mathrm{W}$ in Fig. 3. In both materials, the damaged structure is characterised by a population of helium bubbles that change in density, size and morphology with increasing damage level up to the maximum value of $1 \mathrm{dpa}$ in this work. Fig. 6 displays the evolution of the average bubble size and the number density as it relates to damage level in both materials. The radiation-induced dislocation loops were not detected in any of these materials at $800{ }^{\circ} \mathrm{C}$. A significant number of spherical bubbles of $>1 \mathrm{~nm}$ in diameter are already present in $\mathrm{W}$ at the relatively low damage level of $0.004 \mathrm{dpa}$, which corresponds to a $\mathrm{He}^{+}$fluence of $3.3 \times 10^{14} \mathrm{He}^{+} / \mathrm{cm}^{2}$. Both the average bubble size and density increase continuously up to a damage level of $0.2 \mathrm{dpa}$, where the average size reaches $\sim 3 \mathrm{~nm}$ and the density amounts to $\sim 26 \times 10^{22} / \mathrm{m}^{3}$. At higher damage levels, both the average size and density continue increasing but at a lower rate, and do not reach saturation at the end of the 
experiment. At the maximum damage level of $1 \mathrm{dpa}$, the average size of the bubble population is $3.9(3) \mathrm{nm}$ and the density is $\sim 32 \times 10^{22} / \mathrm{m}^{3}$. Additionally, at damage levels $\geq 0.3$ dpa, the He bubbles gradually change their morphology from spherical to faceted (see insets in Fig. 3 and Fig. 7a). In contrast, there are no visible bubbles in W-5Ta below 0.02 dpa, and the bubble density remains low up to $0.1 \mathrm{dpa}$. Between 0.1 and $0.2 \mathrm{dpa}$, there is a sharp increase in bubble density. At $>0.2$ dpa the density continues to rise at a lower rate than before but still higher than in $\mathrm{W}$ and reaches a value of $\sim 31 \times 10^{22} / \mathrm{m}^{3}$, which is close to the bubble density in $\mathrm{W}$ at the same damage level. Additionally, the average bubble size in W-5Ta undergoes a smaller increase with damage level and seems to saturate at 2.2(3) $\mathrm{nm}$ at $1 \mathrm{dpa}$. That size value is $\sim 1.7$ times smaller than the value measured in $\mathrm{W}$ also at $1 \mathrm{dpa}$. At such damage level, most of the He bubbles in W-5Ta still remain largely spherical (see Fig. 7b). Figure 8 plots the size frequency distribution of helium bubbles showing an increase in size as a function of a damage level up to $1 \mathrm{dpa}$. The histograms reveal a shift in bubble sizes limited to a maximum of $<3.5 \mathrm{~nm}$ and a peak frequency at $<2.5 \mathrm{~nm}$ in $\mathrm{W}-5 \mathrm{Ta}$ and a maximum of $<5 \mathrm{~nm}$ and a peak frequency at $<4 \mathrm{~nm}$ in $\mathrm{W}$ at $1 \mathrm{dpa}$.

\section{Discussion}

The helium irradiated microstructure of $\mathrm{W}$ at $800{ }^{\circ} \mathrm{C}$ is characterised by the presence of a relatively large number of bubbles, whose average size and bubble density change with an increase of a damage level, and addition of Ta content. There was no evidence of dislocation loops at $800^{\circ} \mathrm{C}$. This is supported with data on tungsten-rhenium alloys irradiated with neutrons and tungsten-tantalum alloys irradiated with protons at temperatures up to $800{ }^{\circ} \mathrm{C}[29,45]$. The interstitial dislocation loops would be unstable at this elevated temperature and emit self-interstitial atoms, or glide to the free sample surface. Whereas, tungsten sample irradiated with neutrons at $\mathrm{T}<750{ }^{\circ} \mathrm{C}$ and a damage level of $<1$ dpa are characterised by the presence of dislocation loops, whereas at higher irradiation temperatures 
the irradiated microstructure is dominated by the presence of nm-sized voids and the absence of loops [46]. Generally, both W and W-Ta exhibit microstructures with $\leq 20 \%$ of the area occupied by the radiation-induced bubbles under $40 \mathrm{keV} \mathrm{He}^{+}$exposure up to $1 \mathrm{dpa}$. The helium fluence was reported to exhibit a very limited impact on bubble size in $\mathrm{W}$ at $\mathrm{T}<1200^{\circ} \mathrm{C}$. In tungsten irradiated at $800^{\circ} \mathrm{C}$ by $10 \mathrm{keV}$ helium ions, the average bubble density was found to be around (3.0-4.0) $\times 10^{16} \mathrm{~m}^{-2}$, and the mean bubble size was reported to be between $2.0 \mathrm{~nm}$ and $3.5 \mathrm{~nm}$ which is similar to results obtained in this work $\left(\sim 2 \times 10^{16} \mathrm{~m}^{-2}\right)$ [47].

Helium atom diffusion is the principal factor affecting the helium bubble nucleation and growth processes. Helium has an extremely low solubility and low migration energy in metals [48]. The irradiation temperature $800^{\circ} \mathrm{C}$ in this work corresponds to the annealing stage IV reported to occur in $\mathrm{W}$ between $650-1000^{\circ} \mathrm{C}$, when the radiation-induced vacancies become mobile [49]. In tungsten, substitutional helium atoms tend to form various strong complexes with vacancies, which are considered as the nuclei of the helium bubbles, which preferentially grow by further helium and helium-vacancy absorption [50]. DFT calculations showed that helium will migrate to vacancies rather than remain in interstitial or substitutional sites [51]. Helium atoms are strongly bound with the vacancies because they compensate its negative volume dilatation [52]. The energy barrier was estimated and reported to be quite high $(2.8 \mathrm{eV})$ for a possibility of a direct jump of the He atom from one vacancy to another in $\mathrm{W}$, supposing a great trapping effect between $\mathrm{He}$ and the vacancy in $\mathrm{W}$ [53]. At temperatures $>600^{\circ} \mathrm{C}$ mobility of the He vacancy complexes is reported to increase, which leads to the development of larger (greater than several nanometres) bubbles [54]. Ultimately these implanted $\mathrm{He}$ atoms that are trapped at vacancies may cause helium embrittlement of the material. 
Diffusion in an alloy is more complex than in a single element component where vacancy-helium atom clustering might be retarded due to the existence of solute dopants. The first-principle calculations revealed a repulsive Ta solute-vacancy interaction in $\mathrm{W}$ with a binding energy between $\mathrm{Ta}$ and a monovacancy from -0.1 to $-0.3 \mathrm{eV}$ for the first-to-third nearest-neighbour positions. However, a weak attractive interaction was reported for Ta atom on the neighbouring position perpendicular to the $<111>$ crowdion, resulting in the impeded diffusion of the SIA [55]. Therefore, the solute Ta partly increases the recombination of vacancy with interstitial, and decreases the concentration of point defects, thereby, leading to a reduced vacancy concentration within the matrix. Moreover, the binding energy between a Ta interstitial atom and a $\mathrm{He}$ atom in $\mathrm{W}$, when He was initially situated in the third to first nearest-neighbour sites relatively to a Ta atom, was reported to be $0.1-0.3 \mathrm{eV}$, and the binding energy between the second introduced $\mathrm{He}$ atom and existing $\mathrm{He}-\mathrm{Ta}$ complex was declared to be $1.1 \mathrm{eV}$. This indicates a strong favourable binding effect and consequent trapping of He by substitutional Ta or already formed He-Ta complexes preventing He atom migration in the $\mathrm{W}$ lattice [56]. The consequence of the described above events is a lower probability of interaction between vacancies and He atoms in the vicinity of tantalum atoms.

In addition, the formation energy of a mono-vacancy for the first-to-fourth nearestneighbour positions in W-5Ta alloy was reported to be higher compared to the pure tungsten, suggesting that mono-vacancies are not that easily formed around the Ta atom in $\mathrm{W}$ [57]. delaying vacancy diffusion via a solute drag effect [58], which may retard the vacancy mobility and further binding of a vacancy with $\mathrm{He}$ in $\mathrm{W}$. The formation energy of a He interstitial in the W-5Ta alloy, with the most stable configuration for He in the substitution site, was reported to be lower $(4.56 \mathrm{eV})$ and therefore more favourable compared to the pure tungsten system $(4.92 \mathrm{eV})$ [59]. The formation energies of the He atom in the tetrahedral interstitial site and octahedral interstitial site were also calculated in pure $\mathrm{W}$ and were 
reported to be 6.18 and $6.43 \mathrm{eV}$ which is also higher than in W-Ta alloy (5.50 and $5.84 \mathrm{eV}$ respectively). The helium-vacancy clustering and the ability of bubble formation and their further growth is therefore retarded in the W-Ta system below 0.02 dpa. Whereas in contrast, already at a damage level of $0.004 \mathrm{dpa}$, small bubbles of $>1 \mathrm{~nm}$ have been detected in $\mathrm{W}$ yielding the density of $4.2 \times 10^{20} \mathrm{~m}^{-3}$. Hence, the presence of Ta interferes with helium/vacancy clustering and subsequently delays bubble nucleation causing deceleration of the bubble transition into faceted shape at higher damage levels.

A similar trend in the radiation-induced defect retention was observed in $\mathrm{W}-5 \mathrm{Ta}$ irradiated in-situ by $40 \mathrm{keV}$ protons at $800^{\circ} \mathrm{C}[29,60]$. In comparison with the growing number of voids in $\mathrm{W}$, the voids in $\mathrm{W}-5 \mathrm{Ta}$ were not detected up to a damage level of $0.3 \mathrm{dpa}$, however, the proton irradiation-induced voids became visible when the same sample was post-irradiation annealed at $1000{ }^{\circ} \mathrm{C}$, with a relatively low void density of $4.9 \pm 1.4 \times$ $10^{21} \mathrm{~m}^{-3}$ and an average size of $4.9 \pm 1.4 \mathrm{~nm}$, occurring as a result of the agglomeration of voids by a thermally activated process [29]. And the exposure of W-5Ta to a lower energy of $100 \mathrm{eV} \mathrm{He}{ }^{+}$ions showed similar behaviour with surface fuzz, a result of defect mobility being supressed in comparison to unalloyed $\mathrm{W}$ due to the bigger lattice spacing forced by doping of $\mathrm{W}$ with Ta $[33,61]$. The higher fluence threshold for the formation of surface nano-structuring implies that the W-Ta alloy's surface thermal conductivity will degrade at a slower rate compared to the pure W system during the lifespan of a reactor [62].

The surface effect needs to be taken into account during the in-situ irradiations, especially when the TEM foil thickness is $<100 \mathrm{~nm}$ [63]. The free surface effect was previously observed on the dislocation structure due to the thin foil in the in-situ experiment [31].The ex-situ TEM analysis revealed the coexistence of dislocation tangles and loops in both materials, as opposed to the lack of dislocation tangles in the in-situ specimens. Furthermore there was no change in the nature (i.e. interstitial to vacancy type) of the 
dislocation loops and their Burgers vector, and a significant number of vacancy clusters was also not present, but we did observe the appearance of dislocation tangles in the ex-situ samples. The ex-situ irradiation of bulk tungsten with $\mathrm{He}$ ions of $400 \mathrm{keV}$ showed the formation of larger bubble diameters $(>10 \quad \mathrm{~nm})$ but lower areal bubble density $\left(\sim 10^{16}\right.$ bubbles $\left./ \mathrm{m}^{2}\right)$ compared to the in-situ experiments. This was due to higher amounts of He retained in the irradiated bulk materials while in the in-situ experiments on thin foils some may escape due to the proximity of surfaces [64]. In addition, at higher irradiation temperature the diffusivity ratio of point defect is greater [63]. Hence, considering the influence of the surface effect, the population of the helium bubbles measured in the thin TEM foils is lower than the actual value in bulk would be.

At a damage level $\geq 0.3 \mathrm{dpa}$, the bubbles present in $\mathrm{W}$ develop energetically favourable facets with the facet planes of $\{110\}$, as interpreted by the anisotropy of the surface energy and by the preferential adsorption of diffusing helium ions on specific plane orientations with respect to the bubble surface. The descending order of surface energies in bcc is for low-index planes $\{111\},\{100\}$, and $\{110\}$ with the lowest surface energy for the planes $\{110\}$ due to the greater planar density [65]. To minimize the total free energy, the facets with the lowest surface energy occupy most of the bubble surface along $\{110\}$. The fraction of the faceted bubbles in $\mathrm{W}$ rises and amounts to $>80 \%$ at a maximum of $1 \mathrm{dpa}$. However, the spherical-to-faceted transition of bubble shape is clearly supressed in W-5Ta alloy.

\section{Conclusions}

In-situ analysis of helium bubble formation has been performed in $\mathrm{W}$ and $\mathrm{W}-5 \mathrm{Ta}$ alloy, caused by $40 \mathrm{keV} \mathrm{He}^{+}$irradiation at $800^{\circ} \mathrm{C}$ up to 1 dpa with a maximum He-to-dpa ratio of 5.5 at $\% / d p a$. The extensive use of advanced in-situ TEM characterizations showed the effect of helium fluence and alloying component on the structural morphology of the 
helium bubbles. The spherical bubbles of $>1 \mathrm{~nm}$ were observed in $\mathrm{W}$ at the relatively low damage level of $0.004 \mathrm{dpa}$, which corresponds to a $\mathrm{He}^{+}$fluence of $3.3 \times 10^{14} \mathrm{He}^{+} / \mathrm{cm}^{2}$. The presence of only $5 \mathrm{wt} . \% \mathrm{Ta}$ in solid solution impedes the diffusion of helium ions at $800{ }^{\circ} \mathrm{C}$ and interferes with the binding of He ions with vacancies into complexes, which serve as the core of a helium bubble, and therefore hinders the nucleation of the bubbles $<0.02 \mathrm{dpa}$. Moreover, at $1 \mathrm{dpa},>80 \%$ of the bubbles in $\mathrm{W}$ steadily develops facets, whereas in contrast in W-5Ta bubbles still present a spherical shape.

\section{Acknowledgements}

The authors of this work acknowledge Prof S. E. Donnelly for access to the MIAMI-2 facility (grant ref. EPSRC EP/M028283/1) through the EPSRC funded mid-range facility, the UK National Ion Beam Centre (NS/A000059/1). Authors I.I., M.J.D.R. and S.C.M. are supported through the Sêr Cymru Nuclear Futures Institute funded through WEFO (Wales).

\section{References}

[1] V. Philipps, Tungsten as material for plasma-facing components in fusion devices, J. Nucl. Mater. 2011, 415, S2-S9.

[2] D. Stork, P. Agostini, J.L. Boutard, D. Buckthorpe, E. Diegele, S.L. Dudarev, et al., Developing structural, high-heat flux and plasma facing materials for a near-term DEMO fusion power plant: The EU assessment, J. Nucl. Mater. 2014, 455, 277-291.

[3] T. Hirai, S. Panayotis, V. Barabash, C. Amzallag, F. Escourbiac, A. Durocher, et al., Use of tungsten material for the ITER divertor, Nucl. Mater. Ener. 2016, 9, 616-622.

[4] V. A. Soukhanovskii, A review of radiative detachment studies in tokamak advanced magnetic divertor configurations, Plasma Phys. Control. Fusion. 2017, 59, 064005.

[5] Y. Ueda, J.W. Coenen, G. De Temmerman, R.P. Doerner, J. Linke, V. Philipps, E. Tsitrone, Research status and issues of tungsten plasma facing materials for ITER and beyond, Fusion Eng. Des. 2014, 89, 901-906. 
[6] R. Villari, V. Barabash, F. Escourbiac, L. Ferrand, T. Hirai, V. Komarov, et al., Nuclear analysis of the ITER full-tungsten divertor, Fusion Eng. Des. 2013, 88, 2006-2010.

[7] F. Crescenzia, C. Bachmann, M. Richou, S. Roccella, E. Visca, J.-H. You, Design study of ITER-like divertor target for DEMO, Fusion Eng. Des. 2015, 98-99, 1263-1266.

[8] H. Reimerdes, R. Ambrosino, P. Innocente, A. Castaldo, P. Chmielewski, G. Di Gironimo, et al., Assessment of alternative divertor configurations as an exhaust solution for DEMO, Nucl. Fusion. 2020, 60, 066030.

[9] S. Heuer, Th Weber, G. Pintsuk, J.W. Coenen, J. Matejicek, Ch Linsmeier, Aiming at understanding thermo-mechanical loads in the first wall of DEMO: stress-strain evolution in a Eurofer-tungsten test component featuring a functionally graded interlayer, Fusion Eng. Des. 2018, 135, 141-153.

[10] T.R. Barrett, G. Ellwood, G. Pérez, M. Kovari, M. Fursdon, F. Domptail, t al., Progress in the engineering design and assessment of the European DEMO first wall and divertor plasma facing components, Fusion Eng. Des. 2016, 109-111, 917-924.

[11] P. Sardain, B. Michel, L. Giancarli, A. Li Puma, Y. Poitevin, J. Szczepanski, et al. Fusion Eng. Des. 2003, 69, 769-774.

[12] M. Rieth, S.L. Dudarev, S.M. Gonzalez de Vicente, J. Aktaa, T. Ahlgren, S. Antusch, et al., J. Nucl. Mater. 2013, 442, S173-S180.

[13] M. Barbarino, A. Leonard, N.N. Asakura, M. Jakubowski, M. Kobayashi, B. Lipschutz, et al., Summary of the 3rd IAEA technical meeting on divertor concepts, Nucl. Fusion (In Press).

[14] T. Shen, Y. Dai, Y. Lee, Microstructure and tensile properties of tungsten at elevated temperatures, J. Nucl. Mater. 2016, 468, 348-354.

[15] P. Gumbsch, Brittle fracture and the brittle-to-ductile transition of tungsten, J. Nucl. Mater. 2003, 323, 304-312. 
[16] B. Gludovatz, S. Wurster, A. Hoffmann, R. Pippan, Fracture toughness of polycrystalline tungsten alloys, Int. J. Refract. Metals Hard Mater. 2010, 28, 674-678.

[17] E. Gaganidze, D. Rupp, J. Aktaa, Fracture behaviour of polycrystalline tungsten, J. Nucl. Mater. 2014, 446, 240-245.

[18] H. Bolt, V. Barabash, G. Federici, J. Linke, A. Loarte, J. Roth, K. Sato, Plasma facing and high heat flux materials - Needs for ITER and beyond, J. Nucl. Mater. 2002, 307-311, 43-52.

[19] I.V. Gorynin, V.A. Ignatov, V.V. Rybin, S.A. Fabritsiev, V.A. Kazakov, V.P. Chakin, et al., Effects of neutron irradiation on properties of refractory metals, J. Nucl. Mater. 1992, 191-194, 421-425.

[20] S.J. Zinkle, N.M. Ghoniem, Operating temperature windows for fusion reactor structural Materials, Fusion Eng. Des. 2000, 51-52, 55-71.

[21] N. Baluc, Materials for fusion power reactors, Plasma Phys. Control. Fusion 2006, 48, B165-B177.

[22] N. Yoshida, Review of recent works in development and evaluation of high-Z plasma facing materials, J. Nucl. Mater. 1999, 266-269, 197-206.

[23] M.J. Baldwin, R.P. Doerner, Formation of helium induced nanostructure "fuzz" on various tungsten grades, J. Nucl. Mater. 2010, 404, 165.

[24] S. Kajita, W. Sakaguchi, N. Ohno, N. Yoshida, T. Saeki, Formation process of tungsten nanostructure by the exposure to helium plasma under fusion relevant plasma conditions, Nucl. Fusion 2009, 49, 095005.

[25] M. Rieth, S.L. Dudarev, S.M. Gonzalez de Vicente, J. Aktaa, T. Ahlgren, S. Antusch, et al., A brief summary of the progress on the EFDA tungsten materials program, J. Nucl. Mater. 2013, 442, S173-S180. 
[26] E.Tejado, P.A.Carvalho, A.Muñoz, M.Dias, J.B.Correia, U.V.Mardolcar, J.Y.Pastor, The effects of tantalum addition on the microtexture and mechanical behaviour of tungsten for ITER applications, J. Nucl. Mater. 2015, 467, 949.

[27] D. Jiang, Q. Wang, W. Hu, Z. Wei, J. Tong, H. Wan, The effect of tantalum (Ta) doping on mechanical properties of tungsten (W): a first-principles study, J. Mater. Res. 2016, 31, $3401-3408$

[28] Z. Wang, Y. Yuan, K. Arshad, J. Wang, Z. Zhou, J. Tang, G.-H. Lu, Effects of tantalum concentration on the microstructures and mechanical properties of tungsten-tantalum alloys, Fusion Eng. Des. 2017, 125, 496-502.

[29] I. Ipatova I, R.W. Harrison, S.E. Donnelly, M.J.D. Rushton, S.C. Middleburgh, E. Jimenez-Melero, Void evolution in tungsten and tungsten-5wt.\% tantalum under in-situ proton irradiation at 800 and $1000^{\circ} \mathrm{C}, \mathrm{J} . \mathrm{Nucl}$. Mater. 2019, 526, 151730.

[30] X. Yi, M.L. Jenkins, K. Hattar, P.D. Edmondson, S.G. Roberts, Characterisation of radiation damage in $\mathrm{W}$ and $\mathrm{W}$-based alloys from $2 \mathrm{MeV}$ self-ion near-bulk implantations, Acta Mater. 2015, 92, 163.

[31] I. Ipatova, R.W. Harrison, P.T. Wady, S.M. Shubeita, D. Terentyev, S.E. Donnelly, E. Jimenez-Melero, Structural defect accumulation in tungsten and tungsten-5wt.\% tantalum under incremental proton damage, J. Nucl. Mater. 2018, 501, 329.

[32] H. Zhou, J. Yu, W. Han, L. Cheng, C. Chen, K. Zhu, Large plastic deformation blistering and helium retention in 5\% tantalum doped tungsten under $60 \mathrm{keV}$ helium ions implantation, Fus. Eng. Des. 2018, 134, 43-50.

[33] S. Gonderman, J.K. Tripathi, T. Sizyuk, A. Hassanein, Suppression of surface microstructure evolution in $\mathrm{W}$ and $\mathrm{W}-\mathrm{Ta}$ alloys during simultaneous and sequential He and D ion irradiation in fusion relevant conditions, Nucl. Fusion. 2017, 57, 086001. 
[34] J. Linke, T. Loewenhoff, V. Massaut, G. Pintsuk, G. Ritz, M. Rödig, et al., Performance of different tungsten grades under transient thermal loads, Nucl. Fusion. 2011, 51, 073017.

[35] Y. Zayachuk, M.H.J. t Hoen, P.A. Zeijlmans van Emmichoven, D. Terentyev, I. Uytdenhouwen, G. van Oost, Surface modification of tungsten and tungsten-tantalum alloys exposed to high-flux deuterium plasma and its impact on deuterium retention, Nucl. Fusion. 2013, 53, 013013.

[36] G. Greaves, A.H. Mir, R.W. Harrison, M.A. Tunes, S.E. Donnelly, J.A. Hinks, New Microscope and Ion Accelerators for Materials Investigations (MIAMI-2) system at the University of Huddersfield, Nucl. Instr. Meth. Phys. Res. A. 2019, 931, 37-43.

[37] J.F. Ziegler, Stopping of energetic light ions in elemental matter, J. Appl. Phys. 1999, 85, $1249-1272$

[38] J.F. Ziegler, M.D. Ziegler, J.P. Biersack, SRIM e the stopping and range of ions in matter (2010), Nucl. Instrum. Methods Phys. Res. B. 2010, 268, 1818-1823.

[39] R.E. Stoller, M.B. Toloczko, G.S. Was, A.G. Certain, S. Dwaraknath, F.A. Garner. On the use of SRIM for computing radiation damage exposure. Nucl. Instr. Meth. Phys. Res. B. $2013, \mathbf{3 1 0}, 75-80$.

[40] ASTM E521-96, Standard Practice for Neutron Radiation Damage Simulation by Charged-Particle Irradiation, 2009.

[41] M.L. Jenkins, M.A. Kirk, Characterization of Radiation Damage by Transmission Electron Microscopy, IOP Publishing Ltd. 2001.

[42] S. Suzuki, K. Abe, Topological structural analysis of digitized binary images by border following, Computer Vision, Graphics, and Image Processing. 1985, 30, 32-46

[43] G. Bradski, The OpenCV Library, Dr. Dobb's Journal of Software Tools. 2000.

[44] C.A. Schneider, W.S. Rasband, K.W. Eliceiri, NIH Image to ImageJ: 25 years of image analysis. Nat. Methods. 2012, 9, 671-675. 
[45] M. Fukuda, K. Yabuuchi, S. Nogami, A. Hasegawa, T. Tanaka, Microstructural development of tungsten and tungsten-rhenium alloys due to neutron irradiation in HFIR, J. Nucl. Mater. 455 (2014) 460-463.

[46] A. Hasegawa, M. Fukuda, S. Nogami, K. Yabuuchi, Neutron irradiation effects on tungsten materials, Fusion Eng. Des. 89 (2014) 1568-1572

[47] X. Yi, K. Arakawa, D. Nguyen-Manh, F. Ferroni, P. Liu, W. Han, et al., A study of helium bubble production in $10 \mathrm{keV} \mathrm{He}+$ irradiated tungsten. Fus. Eng. Des. 2017, 125, 454457.

[48] H. Iwakiri, K. Yasunaga, K. Morishita, and N. Yoshida, Microstructure evolution in tungsten during low-energy helium ion irradiation, J. Nucl. Mater. 2000, 283-287, 11341138.

[49] L.K. Keys, J. Moteff, Neutron irradiation and defect recovery of tungsten, J. Nucl. Mater. 1970, 34, 260-280.

[50] X.C. Li, Y.-N, Li,Y. Yu, G.-N. Luo, X. Shu, G.-H. Lu, Helium defects interactions and mechanism of helium bubble growth in tungsten: A molecular dynamics simulation, $J$. Nucl. Mater. 2014, 451, 356-360.

[51] S.-C. Lee, J.-H. Choi, J. G. Lee, Energetics of He and H atoms with vacancies in tungsten: First-principles approach, J. Nucl. Mater. 2009, 383(3), 244-246.

[52] G. D. Samolyuk,Y. N. Osetsky \&R. E. Stoller, Properties of Vacancy Complexes with Hydrogen and Helium Atoms in Tungsten from First Principles, Fusion Sc. Technol. 2017, 71, 52-59.

[53] C. González and R. Iglesias, "Migration mechanisms of helium in copper and tungsten," J. Mater. Sci., vol. 49, no. 23, pp. 8127-8139, 2014. 
[54] Y. Ueda, J.W. Coenen, G. De Temmerman, R.P. Doerner, J. Linke, V. Philipps, et al., Research status and issues of tungsten plasma facing materials for ITER and beyond. Fus. Eng. Des. 2014, 89, 901-906.

[55] X.-S. Kong, X. Wu, Y.-W. You, C.S. Liu, Q.F. Fang, J.-L. Chen et al., First-principles calculations of transition metal-solute interactions with point defects in tungsten. Acta Mater. 2014, 66, 172-183.

[56] X. Wu, X.-S. Kong, Y.-W. You, C.S. Liu, Q.F. Fang, J.-L. Chen et al., Effects of alloying and transmutation impurities on stability and mobility of helium in tungsten under a fusion environment. Nucl. Fusion. 2013, 53, 073049-073058.

[57] S. Wen, K. Hu, M.Pan et al., Effect of transmutation elements Re and Ta on the vacancy formation anddissociation behaviors in W bulk. Comput. Mater. Sci. 2020, 179, 109624.

[58] T. Garnier, M. Nastar, P. Bellon, D.R. Trinkle, Solute drag by vacancies in bodycentered cubic alloys. Phys. Rev. 2013, B 88, 134201.

[59] C. Wan, S.Yu, X.Ju, W.Wang, Hydrogen trapping in helium-implanted W and W-Ta alloy: First-principles approach. J. Nucl. Mater. 2018, 508, 249-256.

[60] F.A. Smidt Jr., J.A. Sprague, Suppression of void nucleation by a vacancy trapping mechanism. Scripta Metall. 1973, 7, 495-501.

[61] S. Gonderman, J.K. Tripathi, T. Sizyuk, A. Hassanein, The effect of low energy helium ion irradiation on tungsten-tantalum (W-Ta) alloys under fusion relevant conditions, J. Nucl. Mater. 2017, 491, 199-205.

[62] T. Novakowski, J. Tripathi, A. Hassanein. Effect of high-flux, low-energy He+ ion irradiation on Ta as a plasma-facing material, Sci. Rep. 2016, 6, 39746.

[63] Y. Li, L. Wang, Y.Yuan, et al, In-situ TEM investigation of $30 \mathrm{keV}$ he+ irradiated tungsten: Effects of temperature, fluence, and sample thickness on dislocation loop evolution, Acta Mater. 2021, 206, 116618. 
[64] R.W. Harrison, N. Peng, R.P. Webb, et al, Characterisation of helium ion irradiated bulk tungsten: A comparison with the in-situ TEM technique, Fusion Eng. Des. 2019, 138, 210216.

[65] E. Aghemenloh, J.O. Umukoro, S.O. Azi, S. Yusuf, J.O.A. Idiodi, Surface energy calculation of bcc metals using the analytical equivalent crystal theory method, J. Nucl. Mater. 2011, 50, 3290-3296.

\section{Figure captions}

Fig. 1. Simulated damage and $\mathrm{He}^{+}$concentration profiles in $\mathrm{W}$ at a damage level of 1 dpa to a He-to-dpa ratio of 5.5 at $\% / d p a$, using the SRIM software with the quick Kinchin-Pease approach and the total current deposited on the sample in the experiment of $0.09 \mathrm{nA}$. The damage level was estimated at each step in the microstructure evolution as the average value in the foil thickness of $\sim 100 \mathrm{~nm}$. According to SRIM calculations, $32 \%$ of the $40 \mathrm{keV}$ He ions was implanted and 56\% was transmitted through the foil.

Fig. 2. A series of images of helium bubbles observed in $\mathrm{W}$ at $800{ }^{\circ} \mathrm{C}$ and a damage level of 1 dpa through the main steps of the bubble detection: (a) bright-field image in under-focus condition, (b) thresholded image with enhanced bubbles, (c) grayscale binary image, (d) estimated contoured areas of detected bubbles

Fig. 3. In-situ observation of the bubble evolution $\mathrm{W}$ at $800{ }^{\circ} \mathrm{C}$ at selected damage levels up to $1 \mathrm{dpa}$ induced by a $40 \mathrm{keV} \mathrm{He}$ ion beam: (a) $0.01 \mathrm{dpa}$, (b) $0.02 \mathrm{dpa}$, (c) $0.05 \mathrm{dpa}$, (d) 0.075 dpa, (e) $0.1 \mathrm{dpa}$, (f) $0.2 \mathrm{dpa}$, (g) $0.3 \mathrm{dpa}$, (h) $0.4 \mathrm{dpa}$, (i) $0.75 \mathrm{dpa}$, (j) $1 \mathrm{dpa}$. The insets show the bubble transition from spherical to faceted at $\geq 0.3 \mathrm{dpa}$. The TEM foil thickness was derived by way of the graphical method from the spacing of the fringes of the CBED patterns and was measured to be $\sim 100 \mathrm{~nm} \pm 10 \%$ 
Fig. 4. In-situ observation of bubble formation in $\mathrm{W}$ at $800{ }^{\circ} \mathrm{C}$ caused by a $40 \mathrm{keV} \mathrm{He}^{+}$ion beam at the relatively low damage levels of: (a) $0.004 \mathrm{dpa}$, (b) $0.008 \mathrm{dpa}$, (c) $0.016 \mathrm{dpa}$. The TEM foil thickness was derived by way of the graphical method from the spacing of the fringes of the CBED patterns and was measured to be $\sim 100 \mathrm{~nm} \pm 10 \%$

Fig. 5. In-situ observation of the bubble evolution $\mathrm{W}-5 \mathrm{Ta}$ at $800^{\circ} \mathrm{C}$ at selected damage levels up to $1 \mathrm{dpa}$ induced by a $40 \mathrm{keV} \mathrm{He}{ }^{+}$ion beam: (a) $0.01 \mathrm{dpa}$, (b) $0.02 \mathrm{dpa}$, (c) $0.04 \mathrm{dpa}$, (d) $0.05 \mathrm{dpa}$, (e) $0.1 \mathrm{dpa}$, (f) $0.2 \mathrm{dpa}$, (g) $0.3 \mathrm{dpa}$, (h) $0.4 \mathrm{dpa}$, (i) $0.75 \mathrm{dpa}$, (j) $1 \mathrm{dpa}$

Fig. 6. Average bubble size and bubble density in $\mathrm{W}$ and $\mathrm{W}-5 \mathrm{Ta}$ alloy at $800{ }^{\circ} \mathrm{C}$ as a function of damage level

Fig. 7. Bright field TEM image of spherical bubbles in W-5Ta and faceted bubbles in W, at $800{ }^{\circ} \mathrm{C}$ and the damage level of $1 \mathrm{dpa}$ induced by a $40 \mathrm{keV} \mathrm{He}{ }^{+}$ion beam. The insets show the electron diffraction patterns taken along the zone axis $<001>$ and $<111>$

Fig. 8 Frequency distribution histograms of helium bubble size showing an increase in size as a function of a damage level in $\mathrm{W}$ and $\mathrm{W}-5 \mathrm{Ta}$ irradiated with $40 \mathrm{keV} \mathrm{He}$ ions to a $\mathrm{He}-$ appm/dpa ratio of 55,000 and dose of $1 \mathrm{dpa}$ 


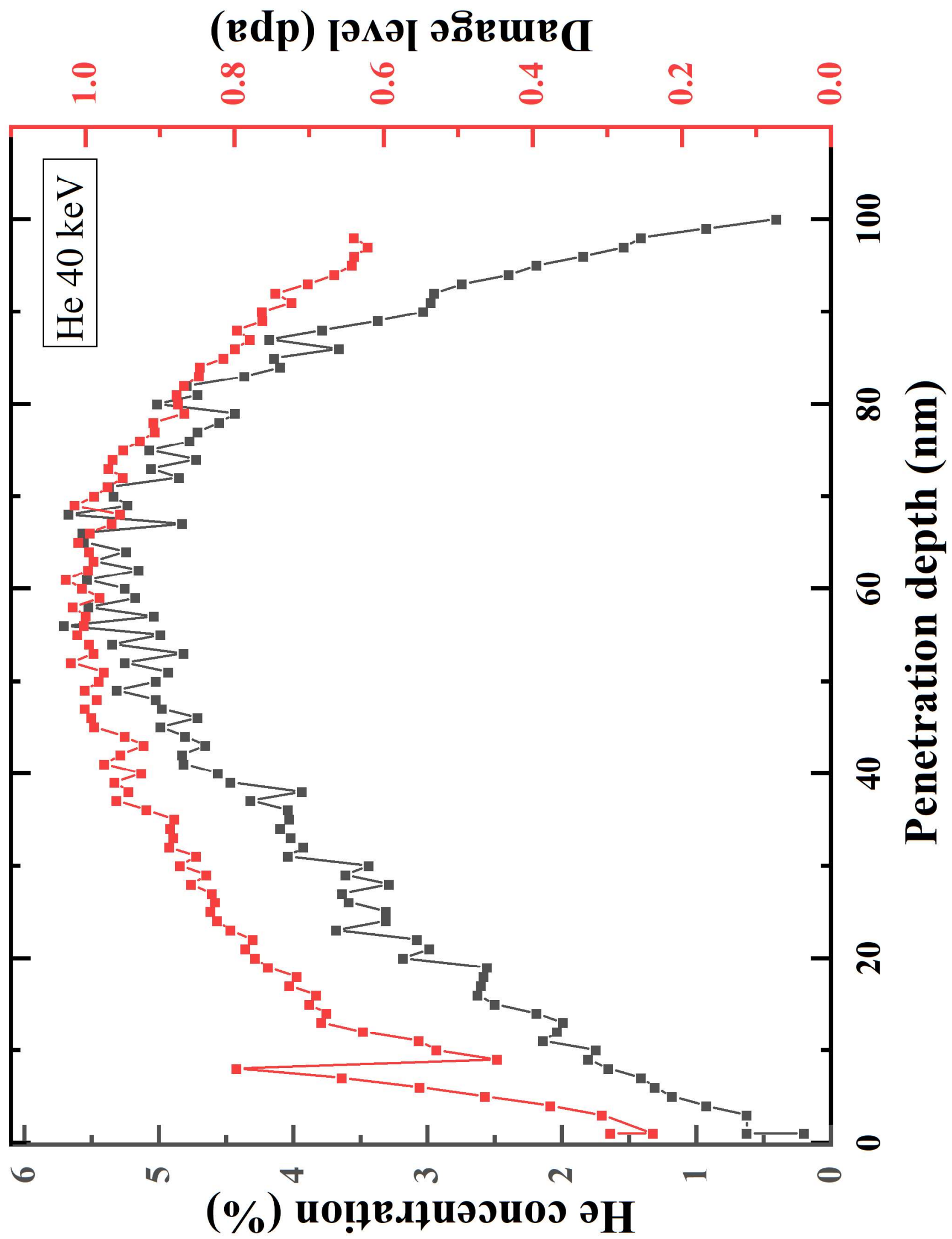




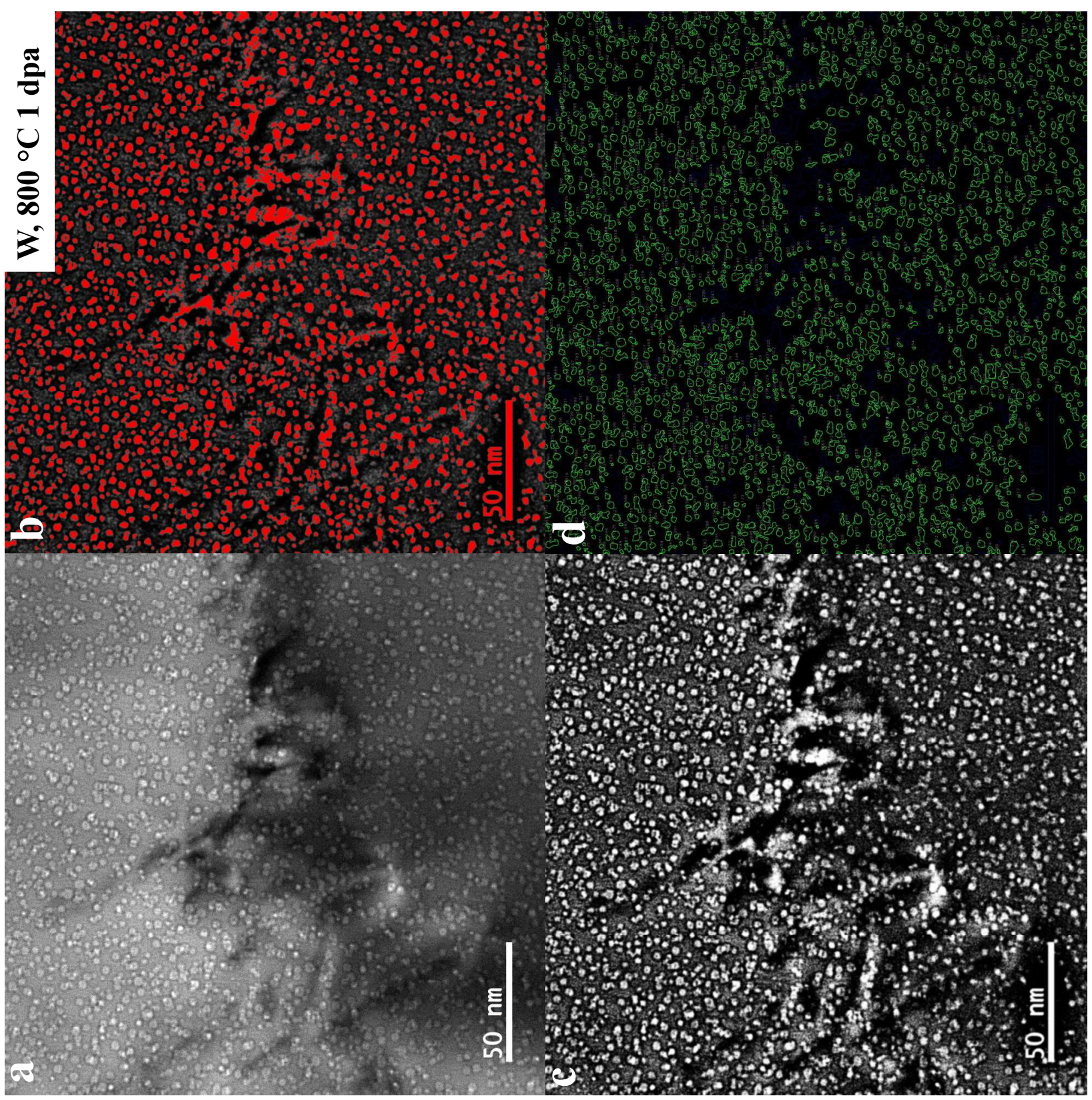




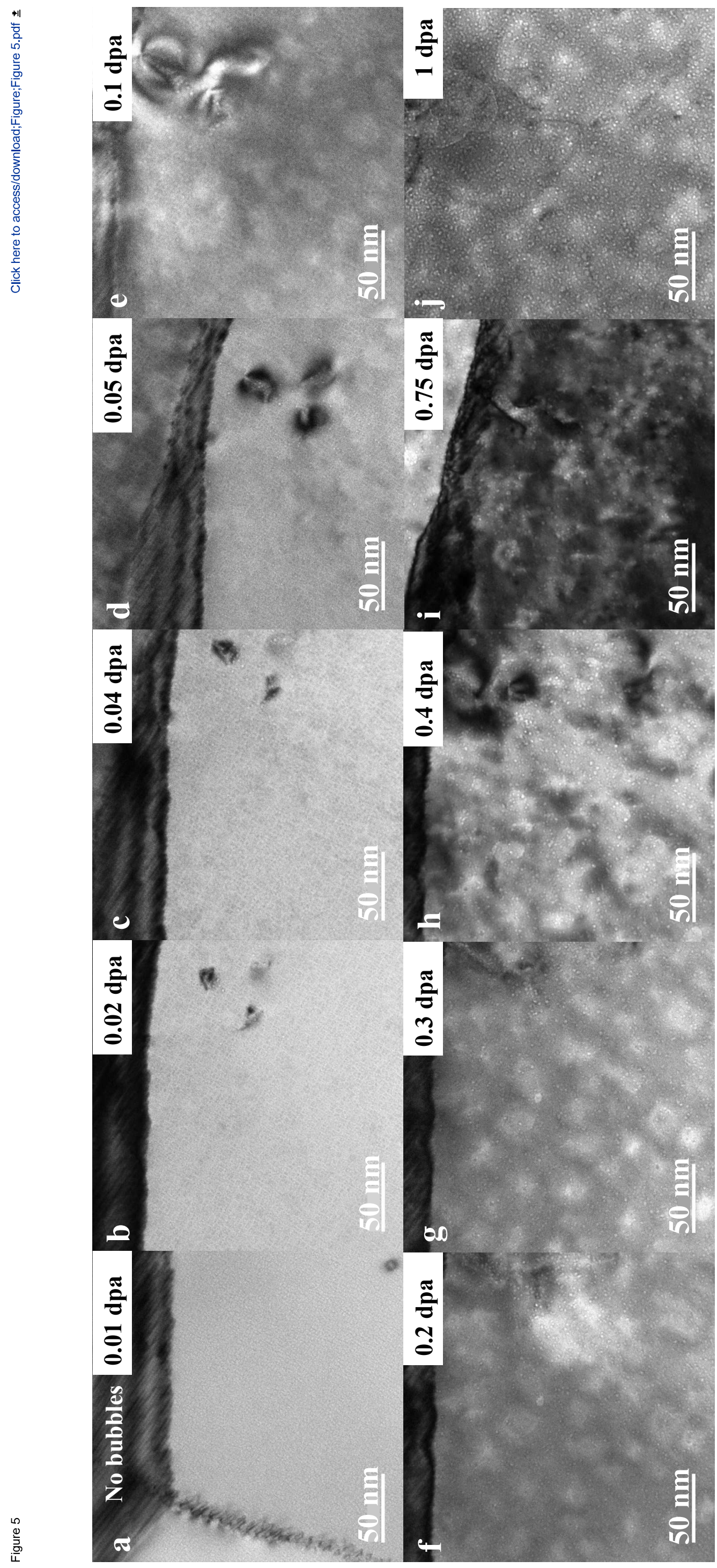




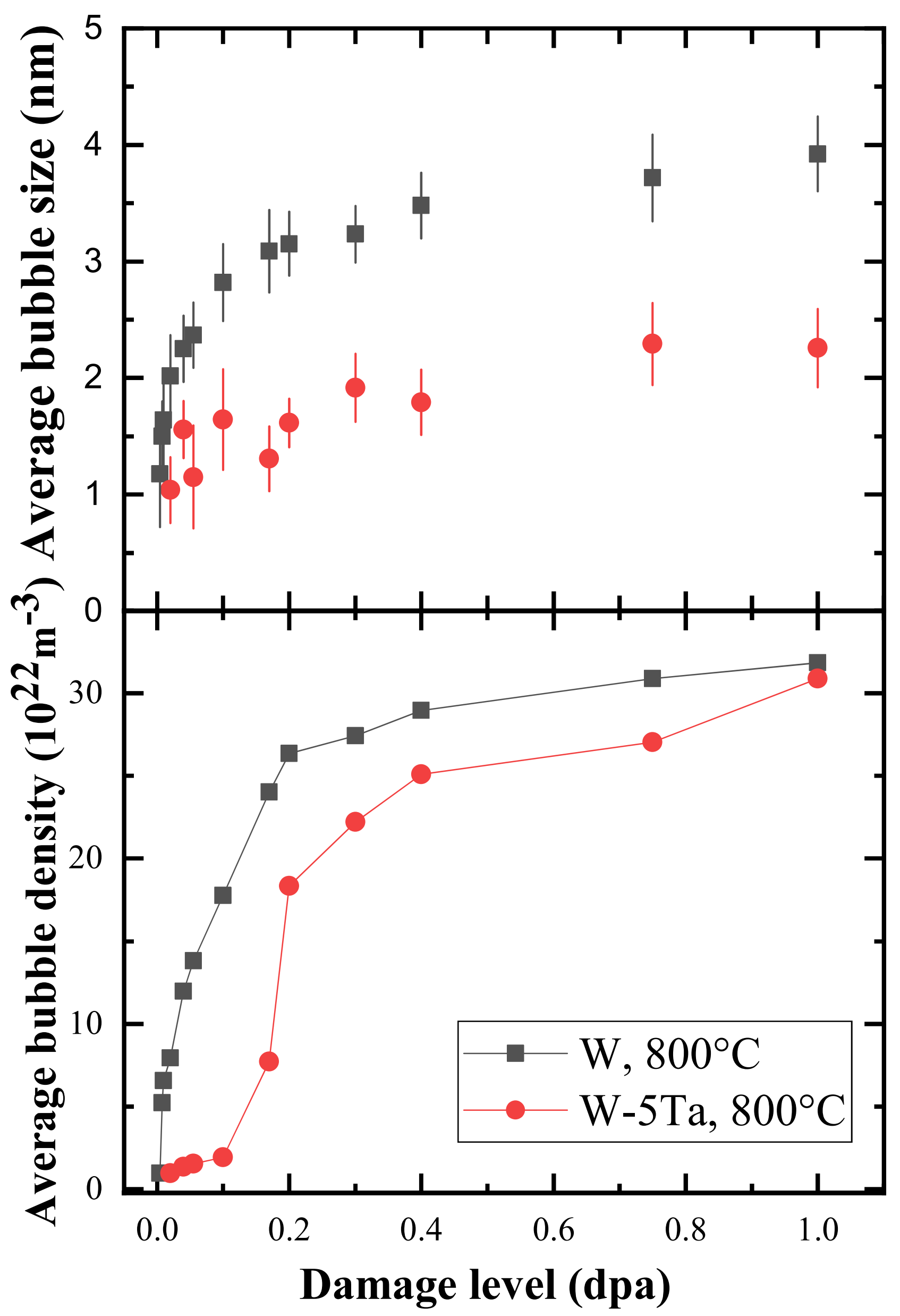




$$
\begin{aligned}
& \begin{array}{l}
\frac{0}{0} \\
0 \\
0 \\
0 \\
2
\end{array}
\end{aligned}
$$

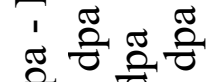

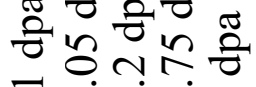

$$
\begin{aligned}
& \text { 官家圆圆园 }
\end{aligned}
$$

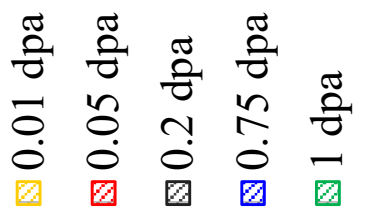

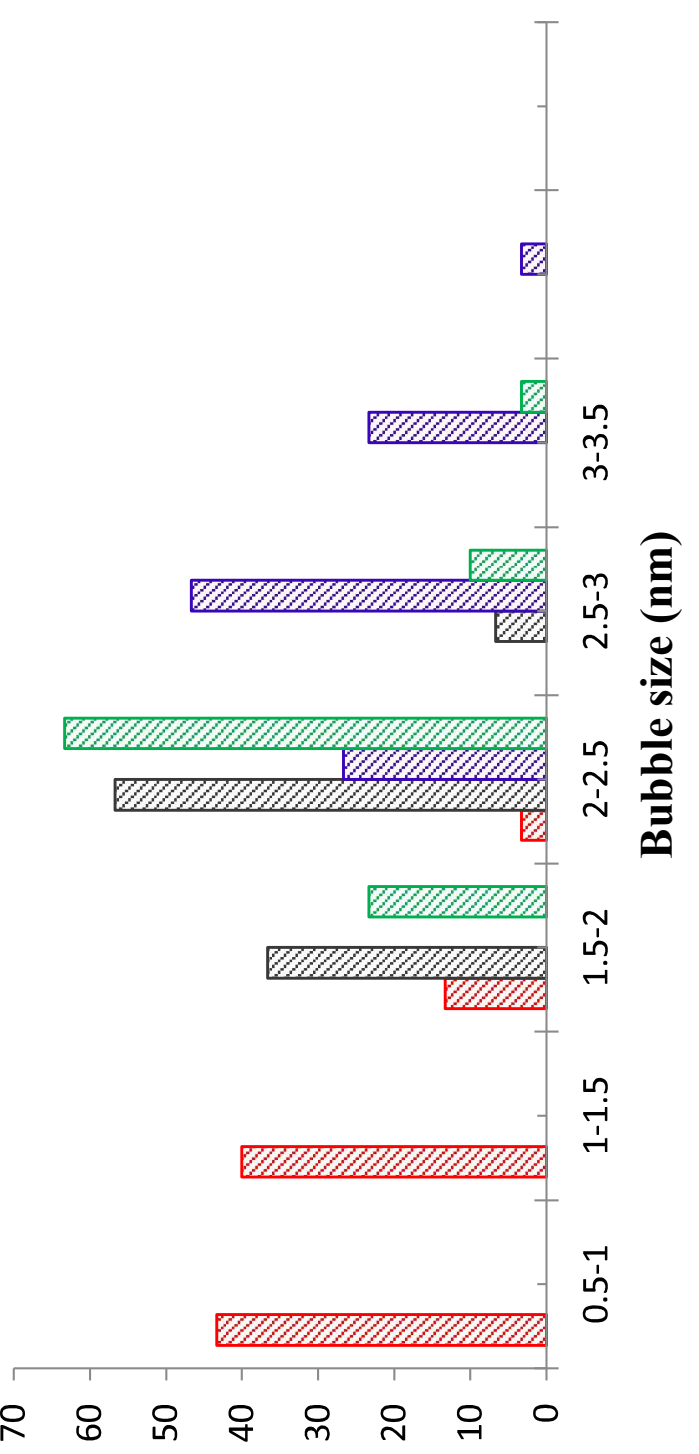

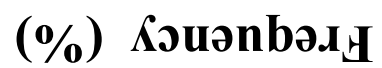

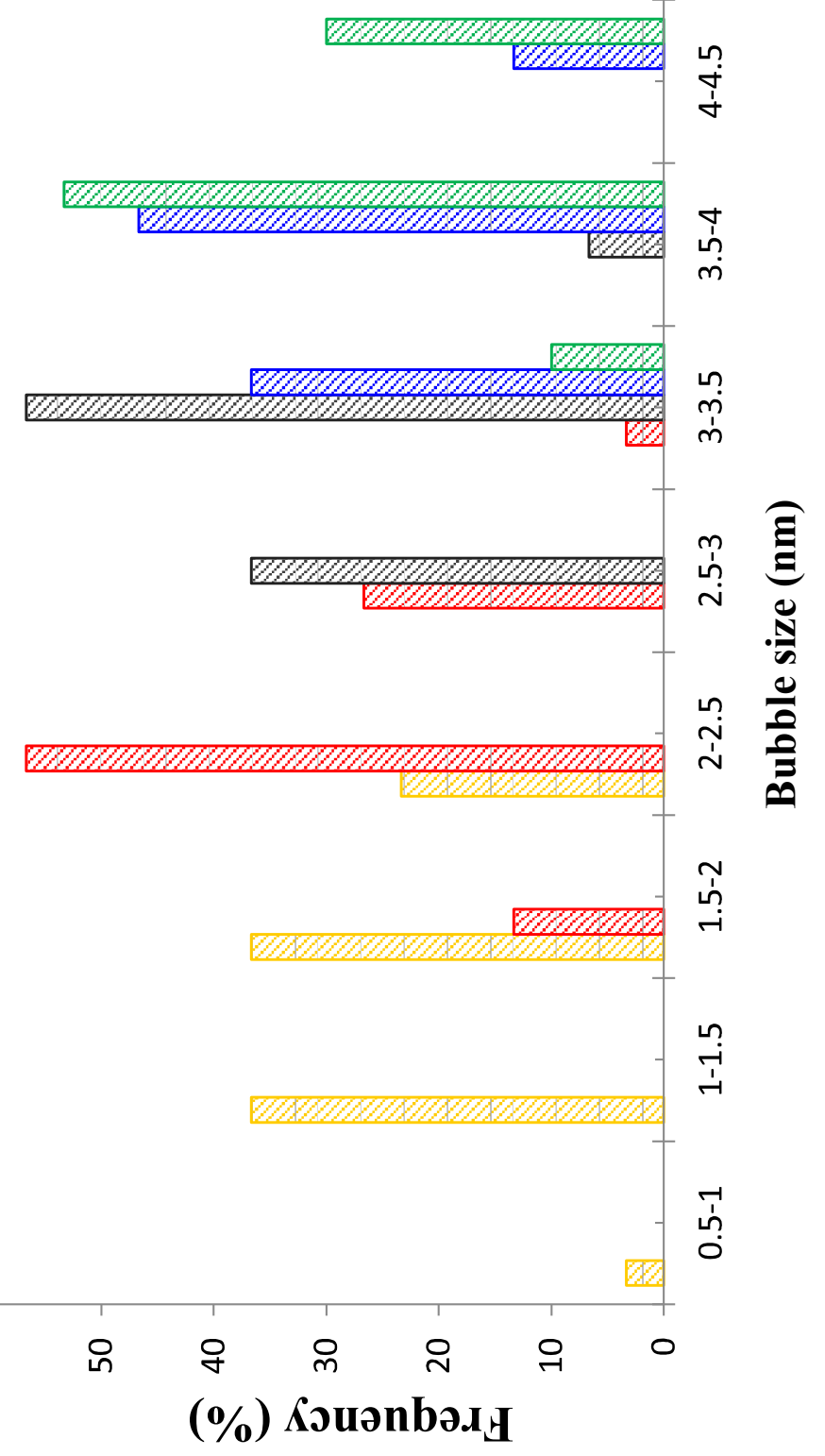




\section{Credit author statement on JNUMA-D-20-00321, I. Ipatova et al.}

The samples were prepared by the main author I. Ipatova, who also analysed and interpreted the data with the valuable input of all the co-authors in their specific areas of expertise.

Regarding the data acquisition, G. Greaves operated the MIAMI-2 TEM/ion accelerator system located at the University of Huddersfield. The main author was always present during the data acquisition, providing input about the regions of interest for detailed characterization.

S. Pacheco-Gutiérrez helped to develop the topologically structured contour detection algorithm in order to determine the number and size of the bubbles.

The main author wrote the manuscript taking into consideration valuable advice of S.C. Middleburgh, M.J.D. Rushton, and E. Jimenez-Melero who provided feedback to the written manuscript. 


\section{Declaration of interests}

$\bigotimes$ The authors declare that they have no known competing financial interests or personal relationships that could have appeared to influence the work reported in this paper.

$\square$ The authors declare the following financial interests/personal relationships which may be considered as potential competing interests: 